\title{
Natural vibration-induced parametric excitation in delaminated Kirchhoff plates
}

Journal of Composite Materials 0 (0) $1-28$

\section{András Szekrényes}

\begin{abstract}
This paper revisits the problem of free vibration of delaminated composite plates with Lévy type boundary conditions. The governing equations are derived for laminated Kirchhoff plates including through-width delamination. The plate is divided into two subplates in the plane of the delamination. The kinematic continuity of the undelaminated part is established by using the system of exact kinematic conditions. The free vibration analysis of orthotropic simply supported Lévy plates reveals that the delaminated parts are subjected to periodic normal and in-plane shear forces. This effect induces parametric excitation leading to the susceptibility of the plates to dynamic delamination buckling during the vibration. An important aspect is that depending on the vibration mode the internal forces have a two-dimensional distribution in the plane of the delamination. To solve the dynamic stability problem the finite element matrices of the delaminated parts are developed. The distribution of the internal forces in the direction of the delamination front was considered. The mode shapes including a half-wave along the width of the plate accompanied by delamination buckling are shown based on the subsequent superimposition of the buckling eigenshapes. The analysis reveals that the vibration phenomenon is amplitude dependent. Also, the phase plane portraits are created for some chosen cases showing some special trajectories.
\end{abstract}

\section{Keywords}

Delamination, free vibration, laminated plate theory, dynamic stability, parametric excitation, harmonic balance, finite element method

\section{Introduction}

Delaminations are typical defects in composite and sandwich structures induced by indentations (e.g. local loading by spherical indentors), ${ }^{1,2}$ low-velocity impact and free edge effects (normal and shear stress concentration between layers at free edges), ${ }^{3-6}$ finally by fabrication defects. ${ }^{7,8}$ The cracks and delaminations reduce significantly the strength and stiffness of composite laminates. ${ }^{9-11}$ The material defects also influence the dynamic behavior of the structures. ${ }^{12-20}$ One of the widely known dynamic phenomena is parametric excitation, which takes place in machine tools, ${ }^{21,22}$ milling processes, ${ }^{23}$ spinning shafts, ${ }^{24}$ railway wheelsets, ${ }^{25,26}$ beams, plates and shells with base excitation, ${ }^{27-30}$ axial $^{31,32}$ or electromagnetic excitation, ${ }^{33}$ beams with piezoelectric absorber, ${ }^{29}$ towers, bridges subjected to different loads, ${ }^{34,35}$ wheel systems ${ }^{36}$ and also typical in different type of oscillators ${ }^{37}$ and pendulums. ${ }^{38}$

This paper was inspired by the really huge literature related to the vibration analysis of delaminated composite beams including dynamic stiffness method, ${ }^{39}$ traditional methods ${ }^{40-43}$ and application even to multiple delaminated beams, ${ }^{44-47}$ finite element (FE) analysis, ${ }^{48,49}$ postbuckled plates, ${ }^{50}$ and solution relative to buckled state. ${ }^{51}$ Moreover, many papers deal with the vibration of delaminated beams with finite element method (FEM), ${ }^{52-55}$ application of Timoshenko beams with delamination ${ }^{56,57}$ including moving loads and masses ${ }^{58-63}$ and elastic foundation. ${ }^{64}$ The solution of the problems is also possible by the differential quadrature method. ${ }^{65}$ The contact between the delamination faces was captured by FEM in

Department of Applied Mechanics, Budapest University of Technology and Economics, Budapest

\section{Corresponding author:}

András Szekrényes, Department of Applied Mechanics, Budapest University of Technology and Economics, Múegyetem rkp. 5, Building MM, IIII, Budapest.

Email: szeki@mm.bme.hu 
Perel $^{66-68}$ recently. Finally, but not least, there are papers analyzing delaminated beams with piezoelectric actuators ${ }^{69,70}$ and investigating damping and dispersion characteristics. ${ }^{71,72}$ For delaminated beams many parametric studies have been published, including effect of delaminations on the mode shapes in composite ${ }^{73-78}$ and sandwich beams. ${ }^{79}$ In Burlayenko and Sadowski, ${ }^{80}$ the foam/core debonding in sandwich plates was investigated during free vibration. However, the existence of the parametric excitation was not revealed in any of the former papers.

To the best of the author's knowledge, the existence of the parametric excitation in the course of free vibration of delaminated composite beams was first revealed in Szekrényes ${ }^{81}$ and was solved effectively by the FE and harmonic balance methods in Szekrényes. ${ }^{82}$ It was also shown that the delamination buckling takes place only if the free vibration amplitude exceeds the so-called critical amplitude at a specified point of the beam. The existence of the critical amplitude was also proved experimentally. The parametric excitation in delaminated plates is possible to appear, as well. Similarly to the theory of laminated and composite beams ${ }^{83-90}$ the literature is very rich in the different theories to model laminated composite plates and shells. Thin flat plates can be modeled by the classical or Kirchhoff plate theory, ${ }^{91,92}$ while for relatively thick plates the first-order shear deformation theory (FSDT or Mindlin), ${ }^{93-100}$ second-order shear deformation theory (SSDT) ${ }^{101-105}$ general third-order theory (TSDT) ${ }^{106-108}$ Reddy third-order theory, ${ }^{109-112}$ other higher-order shear deformation theories (HSDT), ${ }^{113-115}$ layerwise theories, ${ }^{116-121}$ and the 3D elasticity solutions ${ }^{122,123}$ are developed. These theories have been utilized to model curved shells ${ }^{124-126}$ and delaminated and cracked laminates ${ }^{9,10,127-129}$ subsequently in the near past.

In this paper, it is shown that the phenomenon of parametric excitation can take place in free vibrating delaminated plates. Since - to the best of the author's knowledge - there is not available publication for the solution of this problem, the classical (or Kirchhoff) laminated plate theory (CLPT) is applied in this paper. The plate is divided into two parts in the plane of the delamination and the double-plate system is modeled by equivalent single layers (ESLs). The kinematic continuity is established by the system of exact kinematic conditions (SEKC) published in previous papers by Szekrényes. ${ }^{96,110}$ The governing equations are presented and plate problems with Lévy type boundary conditions are solved as examples by the state-space approach. ${ }^{130}$ It is shown that the delaminated part of the plate is subjected to periodic inplane loads leading to parametric excitation and the possibility of delamination buckling during the vibration. The critical loads are determined by a FE model and even the mode shapes are presented for some particular cases. An important finding compared to previous results ${ }^{82}$ is that by increasing the vibration amplitude the subsequent appearance of the first four buckling modes is possible during the vibration.

\section{Governing equations of laminated Kirchhoff plates with delamination}

The basic problem is shown in Figure 1, which is a plate containing a through-width delamination. The through-thickness position of the delamination is asymmetric, i.e. it can be placed between any neighboring plies. Five different regions are indicated in Figure 1: (1) and (5) represent the undelaminated regions, (3) shows the delaminated part, and finally (2) and (4) indicate the left and right delamination fronts. The problem is solved by modeling separately the different parts of the plate. Similar problems under static load have already been solved and published in various literatures. ${ }^{91,96,104,106,109,110}$ Therefore, wherever it is possible the reader will be referred to previous papers. In this paper we investigate the natural vibration of the plate including delamination opening. It is assumed that during the vibration there is no delamination growth. We also assume that the friction between the top and bottom delaminated plates is negligible, the opening and closure of the top and bottom plates take place at the same time in each point and there is no partial opening/closure. Finally, we disregard the oscillatory nature of the stresses, which is typical in interfacial cracks. ${ }^{131}$

\section{Undelaminated part}

The plate is divided into two ESLs ${ }^{132}$ in the plane of the delamination. The thicknesses are $t_{t}$ and $t_{b}$. The inplane displacement components in Kirchhoff plates can be written as ${ }^{132}$

$$
\begin{aligned}
u_{\delta}\left(x, y, z^{(\delta)}, t\right)= & u_{0}(x, y, t)+u_{0 \delta}(x, y, t) \\
& -\frac{\partial w}{\partial x}(x, y, t) \cdot z^{(\delta)} \\
v_{\delta}\left(x, y, z^{(\delta)}, t\right)= & v_{0}(x, y, t)+v_{0 \delta}(x, y, t) \\
& -\frac{\partial w}{\partial y}(x, y, t) \cdot z^{(\delta)}
\end{aligned}
$$

where $u_{0}, v_{0}$ are the global, $u_{0 \delta}$ and $v_{0 \delta}$ are the local membrane displacements, $w(x, y)$ is the transverse deflection and $z^{(\delta)}$ is the local through-thickness coordinate, $\delta=t$ for the top, and $b$ for the bottom plate. The kinematic continuity of the top and bottom plates is 


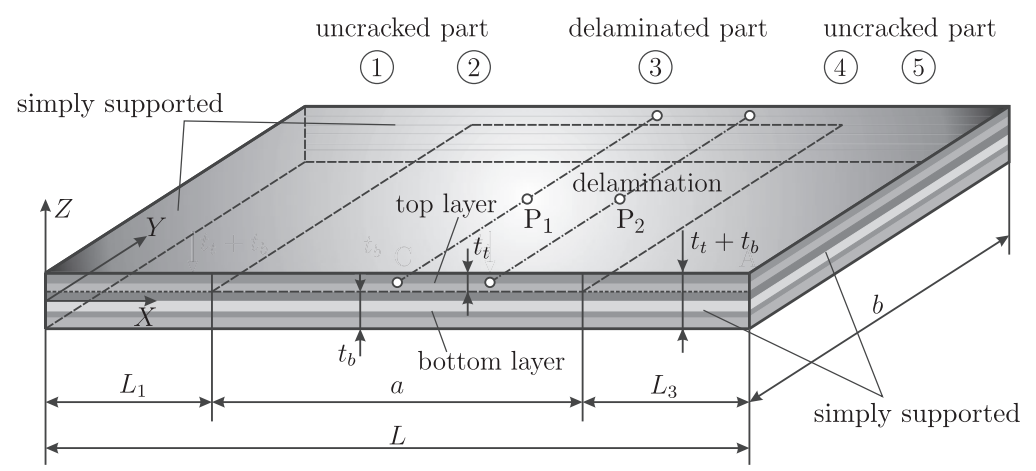

Figure I. Layered composite plate with Lévy-type boundary conditions and through-width delamination.

established by the SEKC $\mathrm{C}^{96,10}$ through the following equations

$$
\begin{aligned}
\left.u_{t}\right|_{z^{(t)}=-\frac{t_{t}}{2}} & =\left.u_{b}\right|_{z^{(b)}=\frac{t_{b}}{2}},\left.\quad v_{t}\right|_{z^{(t)}=-\frac{t_{t}}{2}}=\left.v_{b}\right|_{z^{(b)}=\frac{t_{b}}{2}},\left.\quad w_{t}\right|_{z^{(t)}=-\frac{t_{t}}{2}} \\
& =\left.w_{b}\right|_{z^{(b)}=\frac{t_{b}}{2}}
\end{aligned}
$$

The second set of conditions means that on the global mid-plane of the uncracked part the in-plane displacements are equal to the global membrane displacement components, ${ }^{110}$ i.e.

$$
\frac{t_{t}+t_{b}}{2} \begin{cases}\leq t_{b}: & \left.u_{b}\right|_{z^{(b)}=\frac{t_{t}}{2}}-u_{0}=0,\left.v_{b}\right|_{z^{(b)}=\frac{t_{t}}{2}}-v_{0}=0 \\ \geq t_{b}: & \left.u_{t}\right|_{z^{(t)}=-\frac{t_{b}}{2}}-u_{0}=0,\left.v_{t}\right|_{z^{(t)}=\frac{t_{b}}{2}}-v_{0}=0\end{cases}
$$

Using equations (1) to (3) and eliminating the local membrane displacement parameters leads to the following

$$
\begin{aligned}
& u_{t}\left(x, y, z^{(t)}, t\right)=u_{0}-\frac{\partial w}{\partial x} \cdot\left(\frac{t_{b}}{2}+z^{(t)}\right), \\
& v_{t}\left(x, y, z^{(t)}, t\right)=v_{0}-\frac{\partial w}{\partial y} \cdot\left(\frac{t_{b}}{2}+z^{(t)}\right) \\
& u_{b}\left(x, y, z^{(b)}, t\right)=u_{0}+\frac{\partial w}{\partial x} \cdot\left(\frac{t_{t}}{2}-z^{(b)}\right), \\
& v_{b}\left(x, y, z^{(b)}, t\right)=v_{0}+\frac{\partial w}{\partial y} \cdot\left(\frac{t_{t}}{2}-z^{(b)}\right)
\end{aligned}
$$

namely, the displacement field in the uncracked region depends only upon $u_{0}, v_{0}$ and $w$. The strain field can be calculated by the geometric equation assuming small displacements (or amplitudes) ${ }^{133}$

$$
\varepsilon_{i j}=\frac{1}{2}\left(u_{i, j}+u_{j, i}\right)
$$

The stresses can be determined by using the constitutive law of orthotropic thin plates in the form of $\sigma_{i}^{k}=\bar{C}_{i j}^{(k)} \epsilon_{j}$, where $\bar{C}_{i j}^{(k)}$ is the stiffness matrix of the $k$ th layer in the laminate. ${ }^{134}$ The integration of the stresses in the through-thickness coordinates of both the top and bottom plates results in the matrix equation of laminated thin-walled structures ${ }^{135}$

$$
\left(\begin{array}{l}
\mathbf{N} \\
\mathbf{M}
\end{array}\right)_{(\delta)}=\left(\begin{array}{ll}
\mathbf{A} & \mathbf{B} \\
\mathbf{B} & \mathbf{D}
\end{array}\right)_{(\delta)}\left(\begin{array}{l}
\varepsilon^{(0)} \\
\varepsilon^{(1)}
\end{array}\right)_{(\delta)}
$$

where $\varepsilon^{(0)}$ and $\varepsilon^{(1)}$ represent the vector of constant and linear strains, $\mathbf{N}$ and $\mathbf{M}$ are the vectors of normal forces and bending moments

$$
\mathbf{N}=\left(\begin{array}{lll}
N_{x} & N_{y} & N_{x y}
\end{array}\right)^{T}, \quad \mathbf{M}=\left(\begin{array}{lll}
M_{x} & M_{y} & M_{x y}
\end{array}\right)^{T}
$$

where the vector components are calculated as

$$
\begin{aligned}
\left(\begin{array}{c}
N_{x} \\
N_{y} \\
N_{x y}
\end{array}\right) & =\sum_{k=1}^{N} \int_{z_{k}}^{z_{k+1}}\left(\begin{array}{c}
\sigma_{x} \\
\sigma_{y} \\
\tau_{x y}
\end{array}\right) \mathrm{d} z, \quad\left(\begin{array}{c}
M_{x} \\
M_{y} \\
M_{x y}
\end{array}\right) \\
& =\sum_{k=1}^{N} \int_{z_{k}}^{z_{k+1}}\left(\begin{array}{c}
\sigma_{x} \\
\sigma_{y} \\
\tau_{x y}
\end{array}\right) z \mathrm{~d} z
\end{aligned}
$$

In equation (6), the matrices of extensional, coupling and bending stiffnesses are defined below ${ }^{134}$

$$
\begin{aligned}
& \mathbf{A}=\sum_{k=1}^{N} \overline{\mathbf{C}}^{(k)}\left(z_{k+1}-z_{k}\right), \\
& \mathbf{B}=\frac{1}{2} \sum_{k=1}^{N} \overline{\mathbf{C}}^{(k)}\left(z_{k+1}^{2}-z_{k}^{2}\right), \\
& \mathbf{D}=\frac{1}{3} \sum_{k=1}^{N} \overline{\mathbf{C}}^{(k)}\left(z_{k+1}^{3}-z_{k}^{3}\right)
\end{aligned}
$$


Note that the stiffness matrices are calculated separately for the top and bottom plates with respect to the local mid-planes. ${ }^{96,110}$ Formulating the total potential energy of the system using equations (4) to (8) and applying the principle of virtual work ${ }^{132}$ it is possible to obtain the following equations of motion

$$
\begin{gathered}
\delta u_{0}: \sum_{\delta=t, b}\left(N_{x \delta, x}+N_{x y \delta, y}\right)-\hat{I}_{0} \ddot{u}_{0}+\hat{I}_{1} \ddot{w}_{, x}=0 \\
\delta v_{0}: \sum_{\delta=t, b}\left(N_{x y \delta, x}+N_{y \delta, y}\right)-\hat{I}_{0} \ddot{v}_{0}+\hat{I}_{1} \ddot{w}_{, y}=0 \\
\delta w: \sum_{\delta=t, b}\left(\hat{M}_{x \delta, x x}+2 \hat{M}_{x y \delta, x y}+\hat{M}_{y \delta, y y}\right) \\
\quad-\hat{I}_{0} \ddot{w}-\hat{I}_{1}\left(\ddot{u}_{0, x}+\ddot{v}_{0, y}\right)+\hat{I}_{2} \Delta \ddot{w}=0
\end{gathered}
$$

where the first two of equation (10) govern the inplane vibration of the plate, while the last of equation (10) is related to the transverse motion of the structure. The dot in the equations above means the time derivative. In both cases the coupling between extensional-bending deformation and motion is included. The constants in equation (10) are given below

$$
\begin{aligned}
& \hat{I}_{0}=I_{0 t}+I_{0 b}, \hat{I}_{1}=I_{1 t}+I_{1 b}+I_{0 t} \frac{t_{b}}{2}-I_{0 b} \frac{t_{t}}{2} \\
& \hat{I}_{2}=I_{2 t}+I_{2 b}+I_{1 t} t_{b}-I_{1 b} t_{t}+I_{0 t} \frac{t_{b}^{2}}{4}+I_{0 b} \frac{t_{t}^{2}}{4}
\end{aligned}
$$

where the mass moments of inertia are ${ }^{132}$

$$
\begin{aligned}
& I_{0}=\sum_{k=1}^{N} \rho^{(k)}\left(z_{k+1}-z_{k}\right), \\
& I_{1}=\frac{1}{2} \sum_{k=1}^{N} \rho^{(k)}\left(z_{k+1}^{2}-z_{k}^{2}\right), \\
& I_{2}=\frac{1}{3} \sum_{k=1}^{N} \rho^{(k)}\left(z_{k+1}^{3}-z_{k}^{3}\right)
\end{aligned}
$$

where $\rho^{(k)}$ is the mass density of the $k$ th layer. Apparently, equation (12) is calculated with respect to the local mid-planes. The equivalent bending and twisting moments denoted by the hat in equation (10); moreover, the effective (Kirchhoff) shear force are

$$
\begin{aligned}
\left(\begin{array}{c}
\hat{M}_{x \delta} \\
\hat{M}_{y \delta} \\
\hat{M}_{x y \delta}
\end{array}\right) & =\left(\begin{array}{c}
M_{x \delta} \\
M_{y \delta} \\
M_{x y \delta}
\end{array}\right)+t_{\delta}^{*}\left(\begin{array}{c}
N_{x \delta} \\
N_{y \delta} \\
N_{x y \delta}
\end{array}\right), \\
\hat{V}_{x \delta} & =\frac{\partial \hat{M}_{x \delta}}{\partial x}+2 \frac{\partial \hat{M}_{x y \delta}}{\partial y}
\end{aligned}
$$

where $t_{\delta}^{*}=-t_{b} / 2$ for the top and $t_{t} / 2$ for the bottom plate.

\section{Delaminated part}

In the delaminated part (3) of the plate in Figure 1 the displacement functions are defined as ${ }^{91}$

$$
\begin{aligned}
& u_{\delta}\left(x, y, z^{(\delta)}, t\right)=u_{0 \delta}(x, y, t)-\frac{\partial w}{\partial x}(x, y, t) \cdot z^{(\delta)} \\
& v_{\delta}\left(x, y, z^{(\delta)}, t\right)=v_{0 \delta}(x, y, t)-\frac{\partial w}{\partial y}(x, y, t) \cdot z^{(\delta)}
\end{aligned}
$$

The deflection of the top and bottom plates in the delaminated part are equal to each other, i.e. $w_{t}=w_{b}=w(x, y)$. In other words we apply the constrained mode model. ${ }^{81,136}$ The governing equations of the plate can be derived based on the book by Reddy $^{132}$

$$
\begin{aligned}
\delta u_{0 \delta}: & N_{x \delta, x}+N_{x y \delta, y}-I_{0 \delta} \ddot{u}_{0 \delta}+I_{1 \delta} \ddot{w}_{, x}=0 \\
\delta v_{0 \delta}: & N_{x y \delta, x}+N_{y \delta, y}-I_{0 \delta} \ddot{v}_{0}-I_{1 \delta} \ddot{w}_{, y}=0 \\
\delta w: & \sum_{\delta=t, b}\left(M_{x \delta, x x}+2 M_{x y \delta, x y}+M_{y \delta, y y}\right. \\
& \left.\quad-I_{0 \delta} \ddot{w}-I_{1 \delta}\left(\ddot{u}_{0 \delta, x}+\ddot{v}_{0 \delta, y}\right)+I_{2 \delta} \Delta \ddot{w}\right)=0
\end{aligned}
$$

where we have five equations altogether, because $\delta=t$ or $b$ for the top and bottom plates respectively. In the next section, the solution of the equations of motion for delaminated orthotropic plates with Lévy-type boundary conditions is presented.

\section{Orthotropic Lévy plates with closed delamination}

In accordance with Lévy plate formulation, ${ }^{137,138}$ the following solutions satisfy the simply supported conditions if $y \in[0, b]$

$$
\left(\begin{array}{l}
u_{0}(x, y, t) \\
v_{0}(x, y, t) \\
w(x, y, t)
\end{array}\right)=\left(\begin{array}{c}
U_{0 n}(x) \sin \beta y \\
V_{0 n}(x) \cos \beta y \\
W_{n}(x) \sin \beta y
\end{array}\right) \sin \alpha t
$$

where $\beta=n \pi / b$ ( $b$ is the width of the plate, refer to Figure 1) and $\alpha$ is the free vibration frequency.

\section{Undelaminated part}

Taking equation (16) into equation (10) and simplifying the resulting equations it is possible to 
reduce the system of PDEs into system of ODEs in the form of

$$
\mathbf{Z}^{\prime}=\mathbf{T Z}
$$

which is the state-space model ${ }^{139}$ of the undelaminated regions. The system matrix $\mathbf{T}$ in equation (17) is

$$
\mathbf{T}=\left(\begin{array}{cccccccc}
0 & 1 & 0 & 0 & 0 & 0 & 0 & 0 \\
\hat{h}_{1} & 0 & 0 & \hat{h}_{2} & 0 & \hat{h}_{3} & 0 & \hat{h}_{4} \\
0 & 0 & 0 & 1 & 0 & 0 & 0 & 0 \\
0 & \hat{j}_{1} & \hat{j_{2}} & 0 & \hat{j_{3}} & 0 & \hat{j}_{4} & 0 \\
0 & 0 & 0 & 0 & 0 & 1 & 0 & 0 \\
0 & 0 & 0 & 0 & 0 & 0 & 1 & 0 \\
0 & 0 & 0 & 0 & 0 & 0 & 0 & 1 \\
0 & \hat{n}_{1} & \hat{n}_{2} & 0 & \hat{n}_{3} & 0 & \hat{n}_{4} & 0
\end{array}\right)
$$

where the constants are collected in Appendix 1. The state vector, $\mathbf{Z}$ is

$$
\mathbf{Z}(x)=\left(\begin{array}{llllllll}
U_{0 n} & U_{0 n}^{\prime} & V_{0 n} & V_{0 n}^{\prime} & W_{n} & W_{n}^{\prime} & W_{n}^{\prime \prime} & W_{n}^{\prime \prime}
\end{array}\right)^{T}
$$

The solution of equation (17) can be given in the following form (matrix exponential ${ }^{140}$ )

$$
\mathbf{Z}(x)=\mathbf{A} e^{\mathbf{T} x}
$$

where $\mathbf{A}$ is the vector of constants. The model developed in this section is applied to regions (1) and (5) in Figure 1.

\section{Delaminated part}

In the delaminated part, the solution by equation (16) can be used as well. Based on the previous section, the state-space model of delaminated part (region (3) in Figure 1) can be constructed similarly using equation (15), the results are documented in Reddy ${ }^{132}$ and $\mathrm{Ye},{ }^{139}$ therefore the details are omitted here.

\section{Boundary and continuity conditions}

The boundary conditions (B.C.s) of the plate with simply supported edges at $x=0$ and $x=L$ shown in Figure 1 are

$$
\begin{array}{rlrl}
W_{n}^{(1)}(0) & =0, & V_{0 n}^{(1)}(0)=0, \\
N_{x t}^{(1)}+\left.N_{x b}^{(1)}\right|_{x=0}=0, & \hat{M}_{x t}^{(1)}+\left.\hat{M}_{x b}^{(1)}\right|_{x=0}=0 \\
W_{n}^{(5)}(L) & =0, & & V_{0 n}^{(5)}(L)=0, \\
N_{x t}^{(5)}+\left.N_{x b}^{(5)}\right|_{x=L} & =0, & & \hat{M}_{x t}^{(5)}+\left.\hat{M}_{x b}^{(5)}\right|_{x=L}=0
\end{array}
$$

For built-in edges at $x=0$ and $x=L$ the B.C.s modify to

$$
\begin{aligned}
& W_{n}^{(1)}(0)=0, \quad W_{n}^{(1)}(0)=0, \quad V_{0 n}^{(1)}(0)=0, \\
& N_{x t}^{(1)}+\left.N_{x b}^{(1)}\right|_{x=0}=0 \\
& W_{n}^{(5)}(L)=0, \quad W_{n}^{(5)}(L)=0, \quad V_{0 n}^{(5)}(L)=0, \\
& N_{x t}^{(5)}+\left.N_{x b}^{(5)}\right|_{x=L}=0
\end{aligned}
$$

If the edges at $x=0$ and $x=L$ are free, then the B.C.s become

$$
\begin{array}{cc}
N_{x t}^{(1)}+\left.N_{x b}^{(1)}\right|_{x=0}=0, & N_{x y t}^{(1)}+\left.N_{x y b}^{(1)}\right|_{x=0}=0, \\
M_{x t}^{(1)}+\left.M_{x b}^{(1)}\right|_{x=0}=0, & \hat{V}_{x t}^{(1)}+\left.\hat{V}_{x b}^{(1)}\right|_{x=0}=0 \\
N_{x t}^{(5)}+\left.N_{x b}^{(5)}\right|_{x=L}=0, & N_{x t}^{(5)}+\left.N_{x b}^{(5)}\right|_{x=L}=0, \\
M_{x t}^{(5)}+\left.M_{x b}^{(5)}\right|_{x=L}=0, & \hat{V}_{x t}^{(5)}+\left.\hat{V}_{x b}^{(5)}\right|_{x=L}=0
\end{array}
$$

where $\hat{V}_{x}$ is given by equation (13).

Independently of the B.C.s, the continuity of the membrane displacements in the top and bottom plates of the undelaminated (1) and delaminated (3) regions based on the SEKC requirements become ${ }^{110}$

$$
\begin{aligned}
& U_{0 n t}^{(3)}\left(L_{1}\right)=U_{0 n}^{(1)}-\left.\frac{t_{b}}{2} W_{n}^{\prime}(1)\right|_{x=L_{1}}, \\
& U_{0 n b}^{(3)}\left(L_{1}\right)=U_{0 n}^{(1)}+\left.\frac{t_{t}}{2} W_{n}^{\prime}(1)\right|_{x=L_{1}} \\
& V_{0 n t}^{(3)}\left(L_{1}\right)=V_{0 n}^{(1)}-\left.\frac{t_{b}}{2} \beta W_{n}^{(1)}\right|_{x=L_{1}}, \\
& V_{0 n b}^{(3)}\left(L_{1}\right)=U_{0 n}^{(1)}+\left.\frac{t_{t}}{2} \beta W_{n}^{(1)}\right|_{x=L_{1}}
\end{aligned}
$$

The transverse deflections and the derivatives have to be continuous, as well

$$
W_{n}^{(1)}\left(L_{1}\right)=W_{n}^{(3)}\left(L_{1}\right), \quad W_{n}^{\prime}(1)\left(L_{1}\right)=W_{n}^{\prime}(3)\left(L_{1}\right)
$$

Finally the sum of the in-plane normal forces, inplane shear forces, effective bending moments and effective Kirchhoff shear forces have to be continuous at $x=c$ leading to the conditions below

$$
\begin{gathered}
N_{x t}^{(1)}+\left.N_{x b}^{(1)}\right|_{x=L_{1}}=N_{x t}^{(3)}+\left.N_{x b}^{(3)}\right|_{x=L_{1}}, \\
N_{x y t}^{(1)}+\left.N_{x y b}^{(1)}\right|_{x=L_{1}}=N_{x y t}^{(3)}+\left.N_{x y b}^{(3)}\right|_{x=L_{1}} \\
\hat{M}_{x t}^{(1)}+\left.\hat{M}_{x b}^{(1)}\right|_{x=L_{1}}=\hat{M}_{x t}^{(3)}+\left.\hat{M}_{x b}^{(3)}\right|_{x=L_{1}}, \\
\hat{V}_{x t}^{(1)}+\left.\hat{V}_{x b}^{(1)}\right|_{x=L_{1}}=\hat{V}_{x t}^{(3)}+\left.\hat{V}_{x b}^{(3)}\right|_{x=L_{1}}
\end{gathered}
$$


where in the continuity of equivalent moments and shear forces the conditions suggested in Erdelyi and Hashemi ${ }^{39}$ and Mujumdar and Suryanarayan ${ }^{136}$ have been used, i.e. the moments of the normal and in-plane shear forces are taken into account in the delaminated portion, so $\hat{M}_{x \delta}$ and $\hat{V}_{x \delta}$ are calculated in accordance with equation (13). The conditions between portions (5) and (3) can be derived based on equations (27) to (29). The total number of conditions is 28 . The equations can be given in matrix form, where the determinant of the coefficient matrix is set to zero to get the nontrivial solution

$$
\mathbf{M A}=\mathbf{0}, \quad|\mathbf{M}|=0
$$

It has to be mentioned that the elements of $\mathbf{M}$ contain the vibration frequency $(\alpha)$ explicitly, so the eigenvalues can be obtained by a numerical solution technique (e.g. the bisection method ${ }^{45}$ ) by defining an interval that contains a frequency within. If the frequencies of the plate are determined then even the eigenshapes (transverse deflections) and the strains, stresses, and stress resultants can be calculated.

It will be shown that the top and bottom plates of the delaminated part are subjected to periodic forces (normal and in-plane shear). It means that the stiffness of the delaminated parts is time dependent and the problem is the special case of parametrically excited systems, where the frequency of parametric excitation is equal to one of the free vibration frequencies. This aspect of the problem has been shown in Szekrényes. ${ }^{82}$ It has also been shown that the reason for the delamination opening is the dynamic buckling. The main aim of this work is to carry out the dynamic stability analysis of the delaminated parts. In this respect the top and bottom delaminated plates involve clampedclamped edge conditions at the delamination fronts. Since this problem has no analytical solution, the problem is solved by the FEM. In the subsequent sections, the stiffness, mass, and geometric stiffness matrices of the top and bottom plates of the delaminated part are presented.

\section{Semi-finite element discretization of laminated Lévy plates}

Since the delamination goes across the whole width of the plate we can keep the continuous (Lévy type) solution in the $y$ direction. Therefore, the system should be discretized only in the $x$ direction. The model presented in the sequel is essentially related to the delaminated part and can be used to analyze the top and bottom plates equally. The FE formulation is based on the minimum principle of Hamilton ${ }^{132,139}$

$$
\delta \int_{t_{1}}^{t_{2}} I \mathrm{~d} t=0
$$

where $I=T-U$ is the Hamiltonian; moreover, $T$ is the kinetic energy, $U$ is the strain energy of the system. For a single element these quantities take the form of ${ }^{141}$

$$
\begin{aligned}
U_{e} & =\frac{1}{2} \int_{\Omega_{e}} \sigma_{i j} \varepsilon_{i j} \mathrm{~d} V=\frac{1}{2} \mathbf{u}_{e}^{T} \mathbf{K}_{e} \mathbf{u}_{e}, \\
T_{e} & =\frac{1}{2} \int_{\Omega_{e}} \rho \dot{u}_{i} \dot{u}_{i} \mathrm{~d} V=\frac{1}{2} \dot{\mathbf{u}}_{e}^{T} \mathbf{M}_{e} \dot{\mathbf{u}}_{e}
\end{aligned}
$$

where $\mathbf{K}_{e}, \mathbf{M}_{e}$ are the element mass and stiffness matrices, $\mathbf{u}_{e}$ is the vector of nodal displacements. The total strain and kinetic energy of the system is obtained by adding the element quantities

$$
U=\sum_{N_{e}} U_{e}, \quad T=\sum_{N_{e}} T_{e}
$$

The primary parameters in the standard FE discretization are the displacements and rotations. Figure 2 shows the main parameters of the applied FE type. Due to the continuous solution in the $y$ direction the element is the extension of a simple beam. In accordance with Figure 2 a single FE involves 8 DOFs

$$
\mathbf{u}_{e}^{T}=\left(\begin{array}{llllllll}
u_{01} & v_{01} & w_{1} & \theta_{1} & u_{02} & v_{02} & w_{2} & \theta_{2}
\end{array}\right)
$$

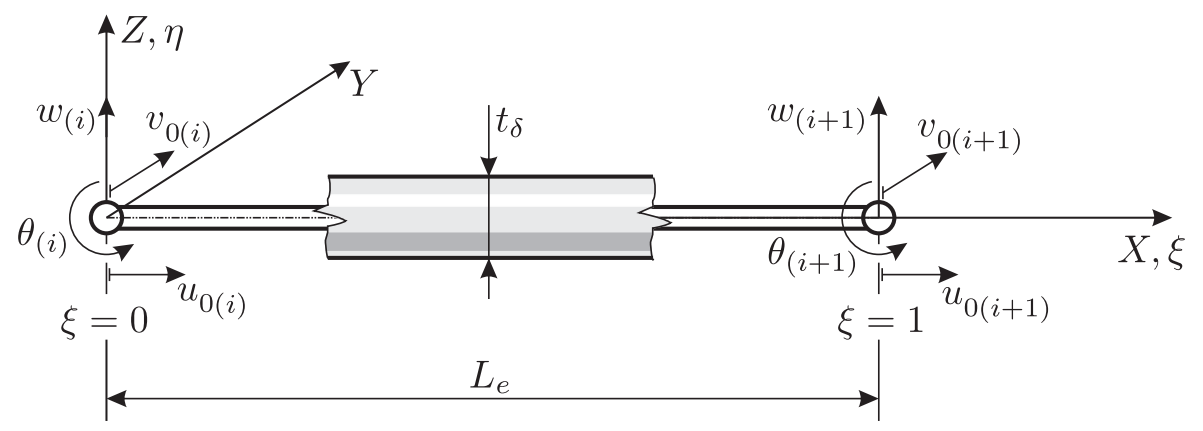

Figure 2. Finite element and nodal parameters for the semi-discretization of Lévy plates. 
where

$$
\left(\begin{array}{c}
u_{0 i} \\
v_{0 i} \\
w_{i} \\
\theta_{i}
\end{array}\right)=\left(\begin{array}{c}
U_{0 i} \sin \beta y \\
V_{0 i} \cos \beta y \\
W_{i} \sin \beta y \\
\vartheta_{i} \sin \beta y
\end{array}\right), \quad i=1,2
$$

is the vector of the semi-discrete displacement parameters. Similarly to some in-plane beam elements the transverse deflection is interpolated by cubic functions, while a linear (Lagrange type) interpolation is applied to the in-plane displacement functions ${ }^{141}$

$$
w(\xi)=a_{0}+a_{1} \xi+a_{2} \xi^{2}+a_{3} \xi^{3}=\sum_{i=1}^{8} N_{w i} u_{e i}=\mathbf{N}_{w} \cdot \mathbf{u}_{e}
$$

where $\xi$ is the dimensionless local coordinate. The angle of rotation of the cross sections about axis $y$ is equal to the derivative of the deflection

$$
\theta(\xi)=\frac{1}{L_{e}} \frac{d w(\xi)}{\mathrm{d} \xi}=\frac{1}{L_{e}}\left(a_{1}+2 a_{2} \xi+3 a_{3} \xi^{2}\right)
$$

where $L_{e}$ is the element length. The in-plane displacements are interpolated as

$$
\begin{aligned}
& u_{0}(\xi)=b_{0}+b_{1} \xi=\sum_{i=1}^{8} N_{u i} u_{e i}=\mathbf{N}_{u} \cdot \mathbf{u}_{e} \\
& v_{0}(\xi)=c_{0}+c_{1} \xi=\sum_{i=1}^{8} N_{v i} u_{e i}=\mathbf{N}_{v} \cdot \mathbf{u}_{e}
\end{aligned}
$$

The nodal conditions to determine the coefficients of the interpolation functions are

$$
\begin{aligned}
w(0) & =w_{1}, \quad w(1)=w_{2}, \quad \theta(0)=\theta_{1}, \quad \theta(1)=\theta_{2} \\
u_{0}(0) & =u_{01}, \quad u_{0}(1)=u_{02}, \quad v_{0}(0)=v_{01}, \quad v_{0}(1)=v_{02}
\end{aligned}
$$

Using equations (36) to (39) it is possible to derive the following interpolation functions

$$
\begin{aligned}
\left\{N_{w 3}, N_{w 4}, N_{w 7}, N_{w 8}\right\}= & \left\{1-3 \xi^{2}+2 \xi^{3}, L_{e}\left(\xi-2 \xi^{2}+\xi^{3}\right),\right. \\
& \left.3 \xi^{2}-2 \xi^{3}, L_{e}\left(\xi^{2}+\xi^{3}\right)\right\}
\end{aligned}
$$

where we obtain the Hermitian shape functions; ${ }^{141}$ moreover, $\left\{N_{w 1}, N_{w 2}, N_{w 5}, N_{w 6}\right\}=0$. The interpolation functions of the in-plane displacements are

$$
\left\{N_{u 1}, N_{u 5}\right\}=\{1-\xi, \xi\},\left\{N_{v 2}, N_{v 5}\right\}=\{1-\xi, \xi\}
$$

and $\left\{N_{u 2}, N_{u 3}, N_{u 4}, N_{u 6}, N_{u 7}, N_{u 8}, N_{v 1}, N_{v 3}, N_{v 4}, N_{v 6}, N_{v 7}\right.$, $\left.N_{v 8}\right\}=0$.

\section{Element stiffness matrices}

Using equation (5) and equations (36) to (39) we can derive the strain components and stress resultants, then by taking these back into equation (32) we obtain the strain energy of the plate as

$$
\begin{aligned}
U_{\delta}= & \frac{1}{2} \int_{(l)}\left(N_{x \delta} \varepsilon_{x \delta}^{(0)}+N_{y \delta} \varepsilon_{y \delta}^{(0)}+N_{x y \delta} \gamma_{x y \delta}^{(0)}\right. \\
& \left.+M_{x \delta} \varepsilon_{x \delta}^{(1)}+M_{y \delta} \varepsilon_{y \delta}^{(1)}+M_{x y \delta} \gamma_{x y \delta}^{(1)}\right) \mathrm{d} x
\end{aligned}
$$

By using the interpolated form of the displacement field variables it is possible to transform equation (42) into

$$
\begin{aligned}
U_{e \delta}= & \frac{1}{2} \mathbf{u}_{e}^{T}\left(\mathbf{K}_{e, n x}^{\delta}+\mathbf{K}_{e, n y}^{\delta}+\mathbf{K}_{e, n x y}^{\delta}+\mathbf{K}_{e, m x}^{\delta}\right. \\
& \left.+\mathbf{K}_{e, m y}^{\delta}+\mathbf{K}_{e, m x y}^{\delta}\right) \mathbf{u}_{e}=\frac{1}{2} \mathbf{u}_{e}^{T} \mathbf{K}_{e}^{\delta} \mathbf{u}_{e}
\end{aligned}
$$

where the matrix terms denoted by $\mathbf{K}$ are stiffness matrices related to the stress resultants of the plate. The stiffness matrices related to the membrane forces are

$$
\begin{gathered}
\mathbf{K}_{e, n x}^{\delta}=\int_{0}^{1}\left(A_{11 \delta} \mathbf{B}_{u \delta} \otimes \mathbf{B}_{u \delta}-B_{11 \delta} \mathbf{B}_{u \delta} \hat{\otimes} \mathbf{B}_{w}\right. \\
\left.+A_{12 \delta} \mathbf{B}_{v \delta} \hat{\otimes} \mathbf{B}_{u \delta}+B_{12 \delta} \mathbf{B}_{w} \hat{\otimes} \mathbf{B}_{u \delta}\right) L_{e} \mathrm{~d} \xi \\
\mathbf{K}_{e, n y}^{\delta}=\int_{0}^{1} \beta\left(-A_{12 \delta} \mathbf{B}_{u \delta} \hat{\otimes} \mathbf{N}_{v \delta}+B_{12 \delta} \mathbf{N}_{v \delta} \hat{\otimes} \widehat{\mathbf{B}}_{w}\right. \\
\left.+A_{22 \delta} \beta \mathbf{N}_{v \delta} \otimes \mathbf{N}_{v \delta}-B_{12 \delta} \beta^{2} \mathbf{N}_{w} \hat{\otimes} \mathbf{N}_{v \delta}\right) L_{e} \mathrm{~d} \xi \\
\mathbf{K}_{e, n x y}^{\delta}=\int_{0}^{1} A_{66 \delta}\left(\beta^{2} \mathbf{N}_{u \delta} \otimes \mathbf{N}_{u \delta}+\beta \mathbf{N}_{u \delta} \hat{\otimes} \mathbf{B}_{v \delta}\right. \\
\left.+\beta \mathbf{N}_{v \delta} \hat{\otimes} \mathbf{B}_{u \delta}+\mathbf{B}_{v \delta} \otimes \mathbf{B}_{v \delta}\right) \\
-B_{66 \delta} \beta\left(\beta \mathbf{N}_{u \delta} \hat{\otimes} \mathbf{B}_{w}+\mathbf{B}_{v \delta} \hat{\otimes} \mathbf{B}_{w}\right) L_{e} \mathrm{~d} \xi
\end{gathered}
$$

where

$$
\mathbf{B}=\frac{1}{L_{e}} \frac{d \mathbf{N}}{\mathrm{d} \xi}, \quad \widehat{\mathbf{B}}=\frac{1}{L_{e}^{2}} \frac{d^{2} \mathbf{N}}{\mathrm{d} \xi^{2}}
$$

Moreover, the stiffness matrices by the bending and twisting moments are

$$
\begin{aligned}
\mathbf{K}_{e, m x}^{\delta}= & \int_{0}^{1}\left(-B_{11 \delta} \mathbf{B}_{u \delta} \hat{\otimes} \widehat{\mathbf{B}}_{w}+D_{11 \delta} \widehat{\mathbf{B}}_{w} \otimes \widehat{\mathbf{B}}_{w}\right. \\
& \left.+B_{12 \delta} \beta \mathbf{N}_{v \delta} \hat{\otimes} \widehat{\mathbf{B}_{w}}-D_{12 \delta} \beta^{2} \mathbf{N}_{w} \hat{\otimes} \widehat{\mathbf{B}}_{w}\right) L_{e} \mathrm{~d} \xi
\end{aligned}
$$




$$
\begin{aligned}
\mathbf{K}_{e, m y}^{\delta}= & \int_{0}^{1} \beta^{2}\left(B_{12 \delta} \mathbf{B}_{u \delta} \hat{\otimes} \mathbf{N}_{w}-D_{12 \delta} \mathbf{N}_{w} \hat{\otimes} \widehat{\mathbf{B}}_{w}\right. \\
& \left.-B_{22 \delta} \beta \mathbf{N}_{v \delta} \hat{\otimes} \mathbf{N}_{w}+D_{22 \delta} \beta^{2} \mathbf{N}_{w} \otimes \mathbf{N}_{w}\right) L_{e} \mathrm{~d} \xi \\
\mathbf{K}_{e, m x y}^{\delta}= & \int_{0}^{1} \beta\left(-2 B_{66 \delta}\left(\beta \mathbf{N}_{u \delta} \hat{\otimes} \mathbf{B}_{w}-\mathbf{B}_{v \delta} \hat{\otimes} \mathbf{B}_{w}\right)\right. \\
& \left.+4 D_{66 \delta} \beta \mathbf{B}_{w} \otimes \mathbf{B}_{w}\right) L_{e} \mathrm{~d} \xi
\end{aligned}
$$

where the special dyadic product is defined below to obtain symmetric matrices

$$
\mathbf{B}_{u \delta} \hat{\otimes} \mathbf{B}_{w}=\frac{1}{2}\left(\mathbf{B}_{u \delta} \otimes \mathbf{B}_{w}+\mathbf{B}_{w} \otimes \mathbf{B}_{u \delta}\right)
$$

\section{Element mass matrix}

The mass matrix of the top and bottom plates is derived based on the kinetic energy of the system ${ }^{141}$

$$
\begin{aligned}
T_{e \delta}= & \frac{1}{2} \int_{(l)}\left(I_{0 \delta}\left(\dot{u}_{0 \delta}^{2}+\dot{v}_{0 \delta}^{2}+\dot{w}^{2}\right)\right. \\
& -2 I_{1 \delta}\left(\dot{u}_{0 \delta} \frac{\partial \dot{w}}{\partial x}+\dot{v}_{0 \delta} \frac{\partial \dot{w}}{\partial y}\right) \\
& \left.+I_{2 \delta}\left\{\left(\frac{\partial \dot{w}}{\partial x}\right)^{2}+\left(\frac{\partial \dot{w}}{\partial y}\right)^{2}\right\}\right) \mathrm{d} x
\end{aligned}
$$

or simply we have: $T_{e \delta}=1 / 2 \cdot \mathbf{u}_{e}^{T} \mathbf{M}_{e}^{\delta} \mathbf{u}_{e}$. Taking back the interpolated displacement variables in equations (36) to (38) leads to

$$
\begin{aligned}
\mathbf{M}_{e}^{\delta}= & \int_{0}^{1}\left(I_{0 \delta}\left(\mathbf{N}_{u \delta} \otimes \mathbf{N}_{u \delta}+\mathbf{N}_{v \delta} \otimes \mathbf{N}_{v \delta}+\mathbf{N}_{w \delta} \otimes \mathbf{N}_{w \delta}\right)\right. \\
& -2 I_{1 \delta}\left(\mathbf{N}_{u \delta} \hat{\otimes} \mathbf{B}_{w}+\beta \mathbf{N}_{v \delta} \hat{\otimes} \mathbf{N}_{w}\right) \\
& \left.+I_{2 \delta}\left(\mathbf{B}_{w} \otimes \mathbf{B}_{w}+\beta^{2} \mathbf{N}_{w} \otimes \mathbf{N}_{w}\right)\right) L_{e} \mathrm{~d} \xi
\end{aligned}
$$

The free vibration analysis of the system can be performed by solving the $\left(\mathbf{K}-\alpha^{2} \mathbf{M}\right) \mathbf{U}=\mathbf{0}$ structural equation for the frequencies and mode shapes. ${ }^{141}$

\section{Element geometric stiffness matrices}

The stability analysis is carried out using the geometric stiffness matrix. The strain energy from the change of stiffness due to the initial stress state can be calculated using the product of the initial stress vector and the vector of large (or von Kármán) ${ }^{124,125}$ strains

$$
\begin{aligned}
U_{G e \delta} & =\frac{1}{2} \int_{(l)}\left\{N_{x}\left(\frac{\partial w}{\partial x}\right)^{2}+2 N_{x y}\left(\frac{\partial w}{\partial x}\right)\left(\frac{\partial w}{\partial y}\right)\right\} \\
d x & =\frac{1}{2} \mathbf{u}_{e}^{T}\left(\mathbf{K}_{G e x}^{\delta}+\mathbf{K}_{G e x y}^{\delta}\right) \mathbf{u}_{e}
\end{aligned}
$$

where $\mathbf{K}_{G e}$ is the geometric stiffness (or stability) matrix of the plate. Using the interpolated form of the field parameters we obtain

$$
\begin{aligned}
\mathbf{K}_{G e x}^{\delta} & =\int_{0}^{1} N_{x} \mathbf{B}_{w} \otimes \mathbf{B}_{w} L_{e} \mathrm{~d} \xi, \\
\mathbf{K}_{G e x y}^{\delta} & =2 N_{x y} \beta L_{e}\left[\mathbf{B}_{w} \hat{\otimes} \mathbf{N}_{w}\right]_{\xi=1 / 2}
\end{aligned}
$$

where the geometric stiffness matrix from the in-plane shear force is calculated by reduced (one-point Gauss) integration $^{141}$ because the exact integration leads to erroneous result. In the sequel the equations for static and dynamic stability analysis are given briefly.

\section{Static stability analysis}

The traditional eigenequation for static stability is ${ }^{142}$

$$
\left(\mathbf{K}^{\delta}+\lambda \mathbf{K}_{G}^{\delta}\right) \mathbf{U}_{\delta}=\mathbf{0}
$$

where $\lambda$ is the load control parameter. By setting the determinant of the matrix term to be equal to zero provides the critical load as $N_{x, c r}=\lambda N_{x}$ or $N_{x y, c r}=\lambda N_{x y}$. The mode shapes are calculated by taking back the load control parameters (eigenvalues) into equation (56). It will be assumed that the eigenshape vectors for static and dynamic buckling are essentially the same.

\section{Static stability with trigonometric widthwise distribution}

It will be shown later that for Lévy plates the distribution of the normal force along the edges of the delaminated part is trigonometric. Figure 3 shows the normal loads of the edges of the top delaminated plate. In the case of the normal force $N_{x}$ the widthwise distribution is sinusoidal if $y \in[0, b]$. However, the solution becomes more simple if we shift the plate in the $y$ direction by $b / 2$, and so the load becomes cosinusoidal (and equivalent to the one in Figure 3) and the problem is solved in the interval of $y \in[-b / 2, b / 2]$. Therefore, equation (52) should be modified as

$$
\left(\mathbf{K}^{\delta}+\lambda \mathbf{K}_{G}^{\delta} \cdot \cos \beta y\right) \mathbf{U}_{\delta}=\mathbf{0}
$$

The solution of equation (57) for a plate loaded with cosinusoidal $N_{x}$ stationery normal force shown by Figure 3 with $y \in[-b / 2, b / 2]$ can be written as

$$
\mathbf{U}_{\delta}=\mathbf{b}_{0}+\sum_{k=1}^{\infty} \mathbf{b}_{k} \cos \frac{k \pi y}{b}
$$




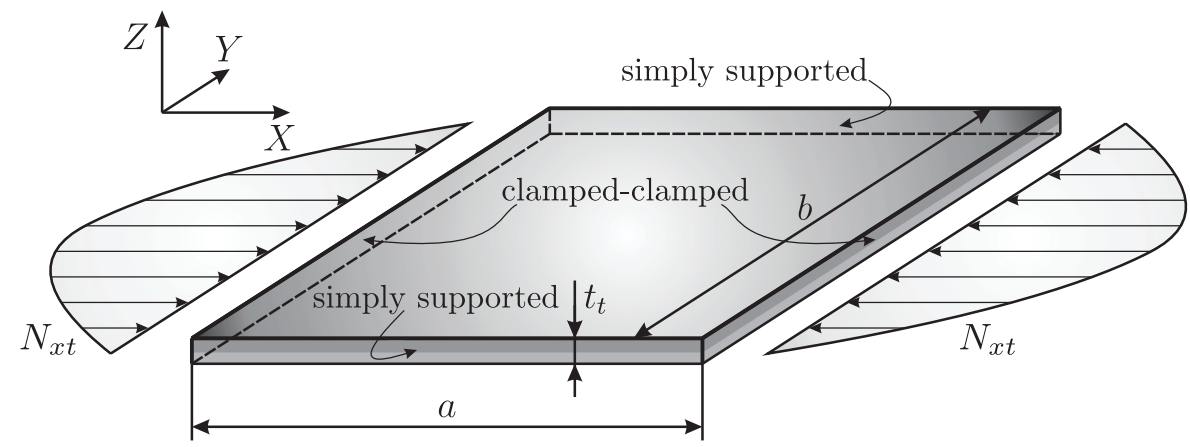

Figure 3. The top plate of the delaminated region loaded by sinusodial $N_{x t}$ normal force.

If the delaminated part is loaded by a cosinusoidal $N_{x y}$ stationery in-plane shear force along the edges then the solution of equation (57) for $y \in[0, b]$ becomes

$$
\mathbf{U}_{\delta}=\sum_{k=1}^{\infty} \mathbf{b}_{k} \sin \frac{k \pi y}{b}
$$

The eigenvalues of equation (57) in both cases can be obtained by using Bolotin's harmonic balance method $^{143,144}$ by taking back equation (58) or equation (59) into equation (57) and by expanding the series solution. The collection of the terms producted by the same trigonometric expression leads to a system of algebraic equations that can be arranged to obtain the following matrix equation in both cases $\left(N_{x}\right.$ and $\left.N_{x y}\right)$

$$
\begin{gathered}
\left(\begin{array}{cccccc}
\mathbf{K}^{\delta} & \frac{1}{2} F_{d} \mathbf{K}_{G 0}^{\delta} & 0 & 0 & 0 & \cdots \\
F_{d} \mathbf{K}_{G 0}^{\delta} & \mathbf{K}^{\delta} & \frac{1}{2} F_{d} \mathbf{K}_{G 0}^{\delta} & 0 & 0 & \cdots \\
0 & \frac{1}{2} F_{d} \mathbf{K}_{G 0}^{\delta} & \mathbf{K}^{\delta} & \frac{1}{2} F_{d} \mathbf{K}_{G 0}^{\delta} & 0 & \cdots \\
0 & 0 & \frac{1}{2} F_{d} \mathbf{K}_{G 0}^{\delta} & \mathbf{K}^{\delta} & \frac{1}{2} F_{d} \mathbf{K}_{G 0}^{\delta} & \cdots \\
0 & 0 & 0 & \frac{1}{2} F_{d} \mathbf{K}_{G 0}^{\delta} & \mathbf{K}^{\delta} & \cdots \\
\vdots & \vdots & \vdots & \vdots & \vdots & \ddots
\end{array}\right) \\
\left(\begin{array}{c}
\mathbf{b}_{0} \\
\mathbf{b}_{1} \\
\mathbf{b}_{2} \\
\mathbf{b}_{3} \\
\mathbf{b}_{4} \\
\vdots
\end{array}\right)=\left(\begin{array}{c}
\mathbf{0} \\
\mathbf{0} \\
\mathbf{0} \\
\mathbf{0} \\
\mathbf{0} \\
\vdots
\end{array}\right) \\
\end{gathered}
$$

where $\mathbf{K}_{G 0}^{\delta}$ is the structural geometric stiffness matrix by setting the $N_{x}$ and $N_{x y}$ forces to unity in equation (55). Moreover, $F_{d}=N_{x}$ in the first of equation (55) and $F_{d}=N_{x y}$ in the second of equation (55). The critical forces are calculated separately for $N_{x}$ and $N_{x y}$ by taking the determinant of matrix on the left side of equation (60) to zero. It is important to note that the effect of the sinusoidal distribution of $N_{x}$ and $N_{x y}$ along the edges on the eigenshape is significant compared to that of the uniformly distributed forces. The determinant becomes divergent if higher than second-order determinant is calculated. It can be seen (refer to equation (58)) that second-order determinant provides the first kinematically possible solution. The ratio of the critical static loads is calculated as: $\lambda_{\beta}=N_{c r}^{\beta} / N_{c r}$, where $N_{c r}$ is the critical load with uniform distribution of $N_{x}$ or $N_{x y}$ in $y, N_{c r}^{\beta}$ is the critical load with sinusoidal or cosinusoidal distribution of the forces. The trigonometric load multiplicator $\lambda_{\beta}$ will be utilized in the dynamic stability analysis.

\section{Dynamic stability with uniform widthwise distribution}

During the vibration of the plate the $N_{x}$ and $N_{x y}$ normal and in-plane shear forces change periodically in the delaminated part inducing parametric excitation and time-dependent stiffness. ${ }^{145-147}$ The model of the dynamic stability analysis was presented in Szekrényes ${ }^{82}$ by adding a small displacement perturbation in the top or bottom plates to the global equation of motion. Because of the fact that the system performs harmonic motion in time, the global terms vanish if the vibration frequency is one of the natural frequencies. It was shown that the dynamic stability analysis has to be carried out only locally and separately for the top and bottom plates of the delaminated part with clamped-clamped conditions. ${ }^{82}$ The equation of motion for the top or bottom plate can be written as

$$
\mathbf{M}^{\delta} \ddot{\mathbf{U}}_{\delta}+\mathbf{K}^{\delta} \mathbf{U}_{\delta}+\mathbf{K}_{G}^{\delta} \cdot \cos \theta t \mathbf{U}_{\delta}=\mathbf{0}
$$

where $\theta$ is the frequency of parametric excitation and equal to one of the free vibration frequencies, $\alpha_{i}$. The solution of equation (61) (system of non-autonomous differential equations) can be written as

$$
\mathbf{U}_{\delta}=\mathbf{\Phi}_{\delta} \hat{T}(t)
$$




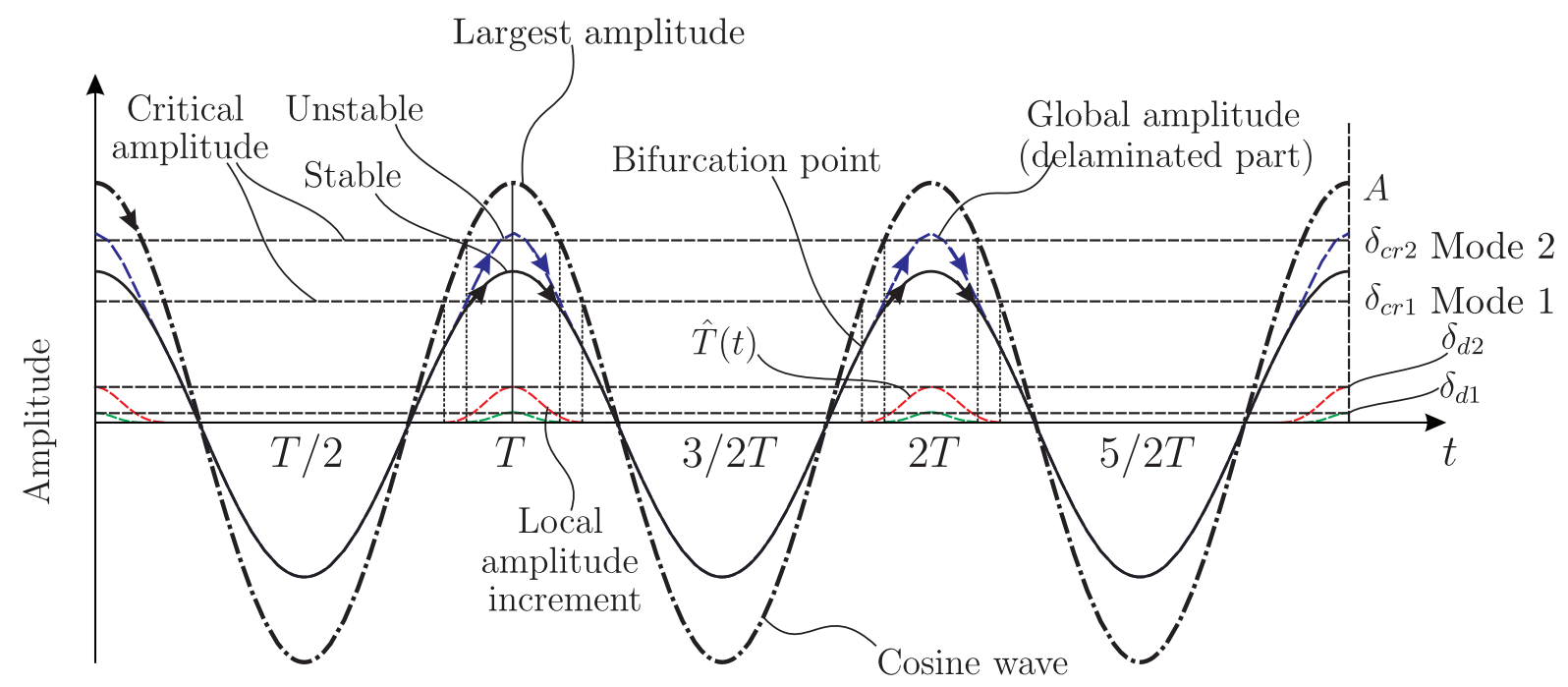

Figure 4. Time function for harmonic motion and subsequent delamination buckling in the upward direction under dynamic conditions.

where $\boldsymbol{\Phi}$ is the local mode shape vector of the delaminated part relative to the free vibration mode shape of the whole plate and $\hat{T}$ is the time function in accordance with Figure 4 and can be given as

$$
\hat{T}(t)=\frac{1}{2} \delta_{d}\left(\cos (\alpha t)-\delta_{c r}+\left|\cos (\alpha t)-\delta_{c r}\right|\right)\left(\delta_{c r}-\cos (\alpha t)\right)^{2}
$$

It is shown in Figure 4 that how the dynamic buckling takes place. The system performs harmonic motion and if a so-called critical amplitude $\left(\delta_{c r 1}\right)$ is reached then the first buckling mode appears. If the amplitude is so high that it exceeds $\delta_{c r 2}$ then even the second buckling eigenshape takes place and the two local eigenmodes are superimposed to the free vibration mode shape. The local increments $\delta_{d 1}$ and $\delta_{d 2}$ in the amplitude can appear only in the upward direction. These aspects show that the vibration is amplitude dependent. Equation (61) - which is a system of Mathieu-Hill DEs $^{144,145,147}$ — can be solved by using the Fourier series of the time function in equation (63)

$$
\begin{aligned}
\hat{T}(t) & =a_{0}+\sum_{k=1,2,3 \ldots}^{\infty} a_{k} \cos (k \alpha t),\left\{a_{0}, a_{k}\right\} \\
& =\left\{a_{0}(c), a_{k}(c)\right\}, \quad k=1,2,3, \ldots,
\end{aligned}
$$

The vector of nodal displacements and accelerations becomes

$$
\begin{aligned}
& \mathbf{U}_{\delta}=\mathbf{a}_{0}+\sum_{k=1,2,3 \ldots}^{\infty} \mathbf{a}_{k} \cos (k \alpha t), \\
& \mathbf{a}_{0}=a_{0} \boldsymbol{\Phi}, \quad \mathbf{a}_{k}=a_{k} \boldsymbol{\Phi}, \quad k=1,2,3, \ldots,
\end{aligned}
$$

$$
\ddot{\mathbf{U}}_{\delta}=-\alpha^{2} \sum_{k=1,2,3 \ldots}^{\infty} \mathbf{a}_{k} k^{2} \cos (k \alpha t), \quad k=1,2,3, \ldots,
$$

Taking these solutions back into equation (61) it is possible to have the following matrix equation

$$
\begin{gathered}
\left(\begin{array}{ccccc}
\mathbf{K}^{\delta} & \frac{1}{2} F_{d} \mathbf{K}_{G 0}^{\delta} & 0 & 0 & \ldots \\
F_{d} \mathbf{K}_{G 0}^{\delta} & \mathbf{K}^{\delta}-\alpha_{i}^{2} \mathbf{M}^{\delta} & \frac{1}{2} F_{d} \mathbf{K}_{G 0}^{\delta} & 0 & \ldots \\
0 & \frac{1}{2} F_{d} \mathbf{K}_{G 0}^{\delta} & \mathbf{K}^{t}-4 \alpha_{i}^{2} \mathbf{M}^{\delta} & \frac{1}{2} F_{d} \mathbf{K}_{G 0}^{\delta} & \ldots \\
0 & 0 & \frac{1}{2} F_{d} \mathbf{K}_{G 0}^{\delta} & \mathbf{K}^{\delta}-9 \alpha_{i}^{2} \mathbf{M}^{\delta} & \ldots \\
\vdots & \vdots & \vdots & \vdots & \ddots
\end{array}\right) \\
\left(\begin{array}{c}
\mathbf{a}_{0} \\
\mathbf{a}_{1} \\
\mathbf{a}_{2} \\
\mathbf{a}_{3} \\
\vdots
\end{array}\right)=\left(\begin{array}{c}
\mathbf{0} \\
\mathbf{0} \\
\mathbf{0} \\
\mathbf{0} \\
\vdots
\end{array}\right)
\end{gathered}
$$

The critical value of the in-plane normal and shear forces $\left(F_{d}=N_{x}\right.$ or $\left.N_{x y}\right)$ can be calculated by taking back any of the free vibration frequencies and equating the determinant of the matrix in equation (66) to zero. It is important to note that the associated mode shapes are calculated from equation (56), in other words it is assumed that the dynamic and static buckling mode shapes are equivalent. The estimated dynamic buckling forces under the action of trigonometric widthwise forces are calculated by producting the critical dynamic forces by the $\lambda_{\beta}$ trigonometric load multiplicator. 


\section{Results and discussions}

The plate with through-width delamination was $b=100 \mathrm{~mm}$ wide, the length of the uncracked portions was $L_{1}=L_{3}=45 \mathrm{~mm}$, the length of the delamination was $a=105 \mathrm{~mm}$. the total thickness of the plate was $t_{t}+t_{b}=4.5 \mathrm{~mm}$. The plate is made of a carbon/ epoxy material, the lay-up of the plate was $\left[ \pm 45^{f} / 0 / \pm 45_{2}^{f} / \overline{0}\right]_{S}$, a single layer was $0.5 \mathrm{~mm}$ thick. The properties of the single laminae are given by Table $1 .{ }^{134}$ Four different positions of the delamination was investigated, these cases are available in Szekrényes. ${ }^{110}$ In case I the thicknesses were: $t_{t}=$ $2.0, t_{b}=2.5 \mathrm{~mm}$, in case II: $t_{t}=1.5, t_{b}=3.0 \mathrm{~mm}$, in case III: $t_{t}=1.0, t_{b}=3.5 \mathrm{~mm}$ and finally in case IV: $t_{t}=0.5, t_{b}=4.0 \mathrm{~mm}$. The analytical and numerical calculations were carried out in the code MAPLE. First, the free vibration analysis of the whole plate was carried out using the analytical model developed in section 2 with closed delamination. The local stability analysis of the delaminated region was performed using the numerical model detailed in the previous section using 14 elements along the $x$ axis. The solution in the $y$ direction is continuous, refer to equation (35).

\section{Natural frequencies and mode shapes}

The frequencies of the plate with simply supported edges at $x=0$ and $x=L$ are calculated for the case when there is only a single half-wave in the widthwise (y) direction, i.e. $n=1$ in $\beta$ (equation (16)). The analysis works even for those cases when several half waves describe the vibration along axis $y$. The frequencies are collected in the first columns of Tables 2 to 5 for cases I and II. Even the whole structure was discretized by the FE method, the numerically computed frequencies are in the second columns of Tables 2 to 5 . The agreement between the numerical and analytical values is excellent in each case. The rest of the tables will be discussed later. For cases III and IV the tables are presented in Appendix 2. The mode shapes of the first four frequencies in case IV are shown in Figure 5, they are as expected. It is important to note that in Figure 5 the constrained mode model is applied and at this stage the possible delamination opening is not yet considered.

The most important aspect of the problem is that the internal forces change periodically in accordance with the free vibration frequency. The other important property is that the internal forces are not uniformly

Table I. Material properties of single carbon/epoxy composite laminates.

\begin{tabular}{|c|c|c|c|c|c|c|c|c|c|c|}
\hline & $\begin{array}{l}E_{x} \\
(\mathrm{GPa})\end{array}$ & $\begin{array}{l}E_{y} \\
(\mathrm{GPa})\end{array}$ & $\begin{array}{l}E_{\mathrm{z}} \\
(\mathrm{GPa})\end{array}$ & $\begin{array}{l}G_{y z} \\
(\mathrm{GPa})\end{array}$ & $\begin{array}{l}G_{x z} \\
(\mathrm{GPa})\end{array}$ & $\begin{array}{l}G_{x y} \\
(\mathrm{GPa})\end{array}$ & $\begin{array}{l}v_{y z} \\
(-)\end{array}$ & $\begin{array}{l}v_{x z} \\
(-)\end{array}$ & $\begin{array}{l}v_{x y} \\
(-)\end{array}$ & $\begin{array}{l}\rho \\
\left(\mathrm{kg} / \mathrm{m}^{3}\right)\end{array}$ \\
\hline $\pm 45^{\circ} f$ & 16.39 & 16.39 & 16.4 & 5.46 & 5.46 & 16.4 & 0.5 & 0.5 & 0.3 & 1580 \\
\hline $0^{\circ}$ & 148 & 9.65 & 9.65 & 4.91 & 4.66 & 3.71 & 0.27 & 0.25 & 0.3 & | 470 \\
\hline
\end{tabular}

Table 2. Critical static and dynamic $N_{x \delta}$ loads of a simply supported plate for the first free vibration frequency - case I.

\begin{tabular}{|c|c|c|c|c|c|c|c|}
\hline $\begin{array}{l}\alpha_{1}^{a n} \\
(\mathrm{~Hz})\end{array}$ & $\begin{array}{l}\alpha_{1}^{F E M} \\
(\mathrm{~Hz})\end{array}$ & $\begin{array}{l}N_{x t, c r}^{\text {stat }} \\
(\mathrm{N} / \mathrm{mm})\end{array}$ & $\begin{array}{l}N_{x t, c r}^{\text {stat } \beta} \\
(\mathrm{N} / \mathrm{mm})\end{array}$ & $\begin{array}{l}\lambda_{\beta} \\
\text { (I) }\end{array}$ & $\begin{array}{l}N_{x t, c r}^{d y n} \\
(\mathrm{~N} / \mathrm{mm})\end{array}$ & $\begin{array}{l}N_{x t, c r}^{d y n, \beta} \\
(\mathrm{N} / \mathrm{mm})\end{array}$ & $\begin{array}{l}\delta_{\text {crit }} \\
(\mathrm{mm})\end{array}$ \\
\hline \multirow[t]{4}{*}{753} & 753 & 92.5 & 130.8 & $1.4 \mid 4$ & 109.8 & 155.3 & 5.59 \\
\hline & & 132.4 & 187.3 & $1.4 \mid 4$ & 120.9 & 171.0 & 6.16 \\
\hline & & 225.3 & 318.7 & 1.414 & 194.5 & 275.1 & 9.92 \\
\hline & & 317.5 & 449.0 & 1.414 & 282.3 & 399.2 & 14.4 \\
\hline$\alpha_{1}^{a n}$ & $\alpha_{1}^{F E M}$ & $N_{x b, c r}^{s t a t}$ & $N_{x b, c r}^{s t a t, \beta}$ & $\lambda_{\beta}$ & $N_{x b, c r}^{d y n}$ & $N_{x b, c r}^{d y n, \beta}$ & $\delta_{\text {crit }}$ \\
\hline$(\mathrm{Hz})$ & $(\mathrm{Hz})$ & $(\mathrm{N} / \mathrm{mm})$ & $(\mathrm{N} / \mathrm{mm})$ & (I) & $(\mathrm{N} / \mathrm{mm})$ & $(\mathrm{N} / \mathrm{mm})$ & $(\mathrm{mm})$ \\
\hline 753 & 753 & 366.4 & 518.1 & 1.414 & 422.7 & 597.7 & 22.0 \\
\hline
\end{tabular}

$\alpha_{i}^{a n}$ : free vibration frequency by analytical solution.

$\alpha_{i}^{F E M}$ : free vibration frequency by finite element solution.

$N_{x \delta, c r}^{\text {stat }}$ : critical load under static condition and uniform widthwise distribution.

$N_{x \delta, c r}^{\text {stat } \beta}$ : critical load under static condition and sinusoidal widthwise distribution.

$\lambda_{\beta}$ : trigonometric load multiplicator.

$N_{x \delta, c r}^{d y n}$ : critical load under dynamic condition and uniform widthwise distribution.

$N_{x \delta, c r}^{d y n}$ : estimated critical load under dynamic condition and sinusoidal widthwise distribution.

$\delta_{\text {crit: }}$ critical amplitude. 
Table 3. Critical static and dynamic $N_{x \delta}$ loads of a simply supported plate for the second free vibration frequency - case I (refer to Table 2 for the notations).

\begin{tabular}{|c|c|c|c|c|c|c|c|}
\hline $\begin{array}{l}\alpha_{1}^{a n} \\
(\mathrm{~Hz})\end{array}$ & $\begin{array}{l}\alpha_{1}^{F E M} \\
(\mathrm{~Hz})\end{array}$ & $\begin{array}{l}N_{x t, c r}^{s t a t} \\
(\mathrm{~N} / \mathrm{mm})\end{array}$ & $\begin{array}{l}N_{x t, c r}^{\text {stat } \beta} \\
(\mathrm{N} / \mathrm{mm})\end{array}$ & $\begin{array}{l}\lambda_{\beta} \\
\text { (I) }\end{array}$ & $\begin{array}{l}N_{x t, c r}^{d y n} \\
(\mathrm{~N} / \mathrm{mm})\end{array}$ & $\begin{array}{l}N_{x t, c r}^{d y n, \beta} \\
(\mathrm{N} / \mathrm{mm})\end{array}$ & $\begin{array}{l}\delta_{\text {crit }} \\
(\mathrm{mm})\end{array}$ \\
\hline \multirow[t]{4}{*}{1355} & 1355 & 34.9 & 49.3 & $1.4 \mid 4$ & 36.2 & 51.2 & 106.1 \\
\hline & & 46.1 & 65.0 & $1.4 \mid 4$ & 52.5 & 74.1 & 153.6 \\
\hline & & I58.| & 223.6 & $1.4 \mid 4$ & 114.6 & 162.0 & 335.9 \\
\hline & & 183.2 & 259.0 & $1.4 \mid 4$ & 162.3 & 229.4 & 475.8 \\
\hline$\alpha_{1}^{a n}$ & $\alpha_{1}^{\mathrm{FEM}}$ & $N_{x b, c r}^{s t a t}$ & $N_{x b, c r}^{s t a t, \beta}$ & $\lambda_{\beta}$ & $N_{x b, c r}^{d y n}$ & $N_{x b, c r}^{d y n, \beta}$ & $\delta_{\text {crit }}$ \\
\hline$(\mathrm{Hz})$ & $(\mathrm{Hz})$ & $(\mathrm{N} / \mathrm{mm})$ & $(\mathrm{N} / \mathrm{mm})$ & (I) & $(\mathrm{N} / \mathrm{mm})$ & $(\mathrm{N} / \mathrm{mm})$ & $(\mathrm{mm})$ \\
\hline 1355 & 1355 & 1853 & 2620 & $1.4 \mid 4$ & 1554 & 2197 & 516 \\
\hline
\end{tabular}

Table 4. Critical static and dynamic $N_{x \delta}$ loads of a simply supported plate for the first free vibration frequency - case II (refer to Table 2 for the notations).

\begin{tabular}{|c|c|c|c|c|c|c|c|}
\hline $\begin{array}{l}\alpha_{1}^{a n} \\
(\mathrm{~Hz})\end{array}$ & $\begin{array}{l}\alpha_{1}^{F E M} \\
(\mathrm{~Hz})\end{array}$ & $\begin{array}{l}N_{x t, c r}^{s t a t} \\
(\mathrm{~N} / \mathrm{mm})\end{array}$ & $\begin{array}{l}N_{x t, c r}^{s t a t, \beta} \\
(\mathrm{N} / \mathrm{mm})\end{array}$ & $\begin{array}{l}\lambda_{\beta} \\
\text { (I) }\end{array}$ & $\begin{array}{l}N_{x t, c r}^{d y n} \\
(\mathrm{~N} / \mathrm{mm})\end{array}$ & $\begin{array}{l}N_{x t, c r}^{d y n, \beta} \\
(\mathrm{N} / \mathrm{mm})\end{array}$ & $\begin{array}{l}\delta_{\text {crit }} \\
(\mathrm{mm})\end{array}$ \\
\hline \multirow[t]{4}{*}{792} & 792 & 40.6 & 57.4 & 1.41 & 53.5 & 75.6 & 2.49 \\
\hline & & 58.3 & 82.4 & $1.4 \mid 4$ & 98.6 & 139.4 & 4.61 \\
\hline & & 98.1 & 138.7 & 1.414 & 148.2 & 209.6 & 6.93 \\
\hline & & 137.5 & 194.0 & 1.414 & 202.1 & 285.7 & 9.44 \\
\hline$\alpha_{1}^{a n}$ & $\alpha_{1}^{F E M}$ & $N_{x b, c r}^{s t a t}$ & $N_{x b, c r}^{\text {stat }, \beta}$ & $\lambda_{\beta}$ & $N_{x b, c r}^{d y n}$ & $N_{x b, c r}^{d y n, \beta}$ & $\delta_{\text {crit }}$ \\
\hline$(\mathrm{Hz})$ & $(\mathrm{Hz})$ & $(\mathrm{N} / \mathrm{mm})$ & $(\mathrm{N} / \mathrm{mm})$ & (I) & $(\mathrm{N} / \mathrm{mm})$ & $(\mathrm{N} / \mathrm{mm})$ & $(\mathrm{mm})$ \\
\hline 792 & 792 & 500.3 & 708.3 & 1.414 & 565.7 & 800.0 & 12.7 \\
\hline
\end{tabular}

Table 5. Critical static and dynamic $N_{x \delta}$ loads of a simply supported plate for the second free vibration frequency - case II (refer to Table 2 for the notations).

\begin{tabular}{|c|c|c|c|c|c|c|c|}
\hline $\begin{array}{l}\alpha_{1}^{a n} \\
(\mathrm{~Hz})\end{array}$ & $\begin{array}{l}\alpha_{I}^{F E M} \\
(\mathrm{~Hz})\end{array}$ & $\begin{array}{l}N_{x t, c r}^{\text {stat }} \\
(\mathrm{N} / \mathrm{mm})\end{array}$ & $\begin{array}{l}N_{x t, c r}^{\text {stat }, \beta} \\
(\mathrm{N} / \mathrm{mm})\end{array}$ & $\begin{array}{l}\lambda_{\beta} \\
\text { (I) }\end{array}$ & $\begin{array}{l}N_{x t, c r}^{d y n} \\
(\mathrm{~N} / \mathrm{mm})\end{array}$ & $\begin{array}{l}N_{x t, c r}^{d y n, \beta} \\
(\mathrm{N} / \mathrm{mm})\end{array}$ & $\begin{array}{l}\delta_{\text {crit }} \\
(\mathrm{mm})\end{array}$ \\
\hline \multirow[t]{4}{*}{1420} & 1420 & 66.2 & 93.7 & 1.414 & 47.8 & 67.6 & 30.4 \\
\hline & & 89.9 & 127.2 & $1.4 \mid 4$ & 82.1 & 116.1 & 52.2 \\
\hline & & 283.8 & 401.4 & 1.414 & 109.9 & 155.4 & 69.9 \\
\hline & & 340.9 & 482.1 & 1.414 & 142.3 & 201.2 & 90.5 \\
\hline$\alpha_{1}^{a n}$ & $\alpha_{1}^{\mathrm{FEM}}$ & $N_{x b, c r}^{\text {stat }}$ & $N_{x b, c r}^{\text {stat }, \beta}$ & $\lambda_{\beta}$ & $N_{x b, c r}^{d y n}$ & $N_{x b, c r}^{d y n, \beta}$ & $\delta_{\text {crit }}$ \\
\hline$(\mathrm{Hz})$ & $(\mathrm{Hz})$ & $(\mathrm{N} / \mathrm{mm})$ & $(\mathrm{N} / \mathrm{mm})$ & (I) & $(\mathrm{N} / \mathrm{mm})$ & $(\mathrm{N} / \mathrm{mm})$ & $(\mathrm{mm})$ \\
\hline 1420 & 1420 & 1955 & 2764 & 1.414 & 1649 & 2332 & 1042 \\
\hline
\end{tabular}

distributed in the delaminated part of the plate, neither along $x$ nor $y$. The major part of the literature deals with cases including uniform force distributions; however, it can be seen in Figure 6(a) that the $N_{x t}$ normal force (in case IV, first natural frequency) is nonuniformly distributed in the delaminated part. For the second frequency Figure 6(a) demonstrates the whole distribution. It has to be highlighted that the normal force is compressive in the first half of the delaminated area and tensile for the other. To the best of the author's knowledge this feature of the problem has not yet been discovered. 

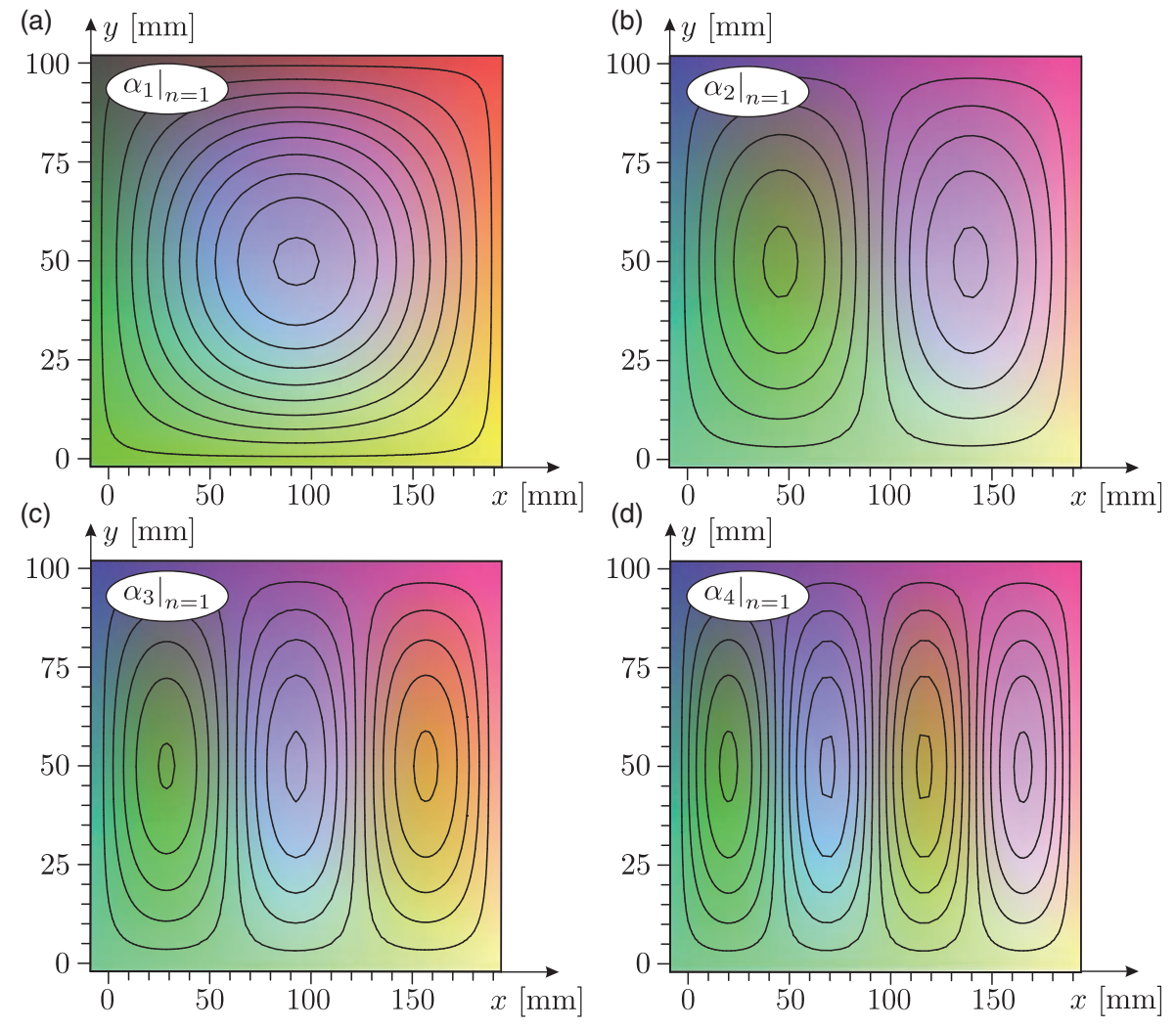

Figure 5. Eigenshapes for the first four natural frequencies of a simply supported delaminated plate with $n=1, \alpha_{1}=886 \mathrm{~Hz}$, $\alpha_{2}=1829 \mathrm{~Hz}, \alpha_{3}=34 \mathrm{II} \mathrm{Hz}$ and $\alpha_{4}=5639 \mathrm{~Hz}$.
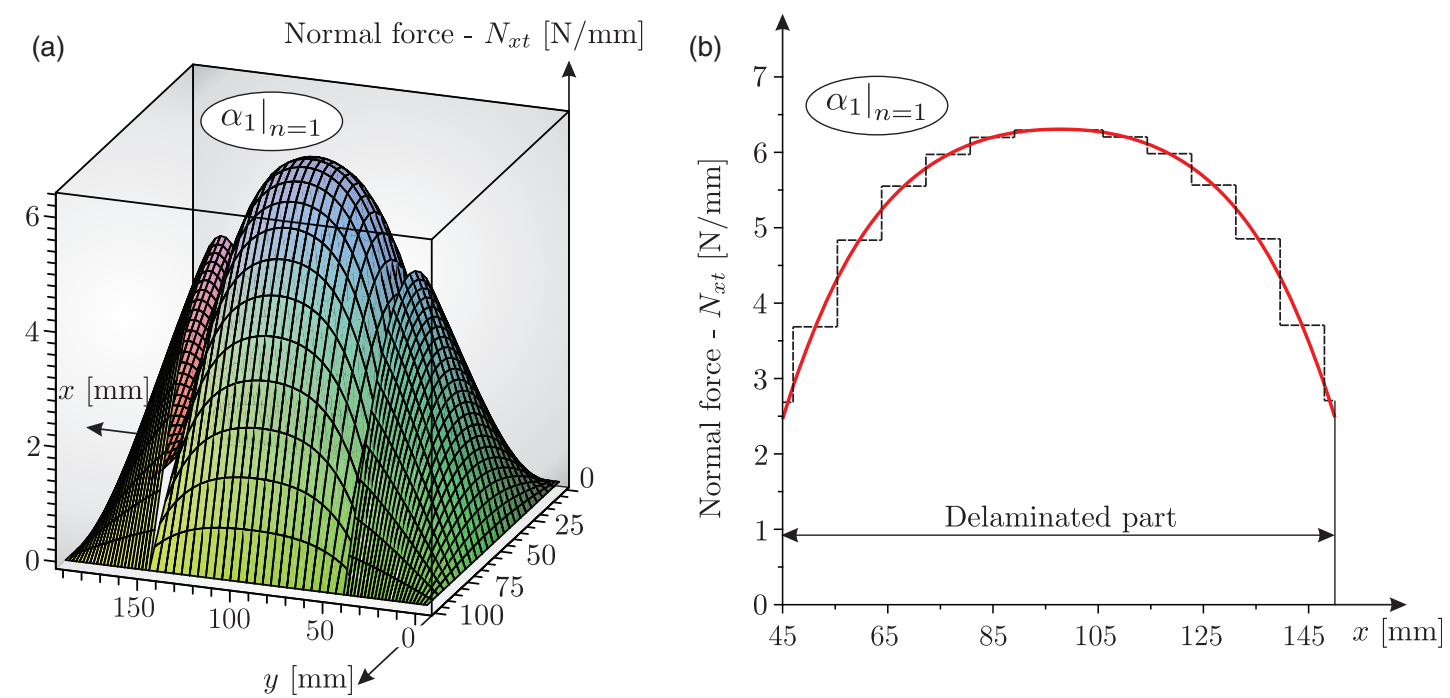

Figure 6. Distribution of the normal force, $N_{x t}$ in the top plate of the delaminated part of a simply supported plate in case IV, first vibration frequency (a). Piecewise constant approximation of the distribution for FE stability analysis (b).

Apart from the in-plane normal force even the inplane shear force $N_{x y}$ acts in the plate at the same time. In case IV, Figures 8(a) and 9(a) depict the distribution of the in-plane shear force in the top plate of the delaminated part for the first and second vibration frequencies. The widthwise distribution is given by cosine functions, the distribution in $x$ is even nonuniform. The change of the forces along $x$ has to be considered in the 

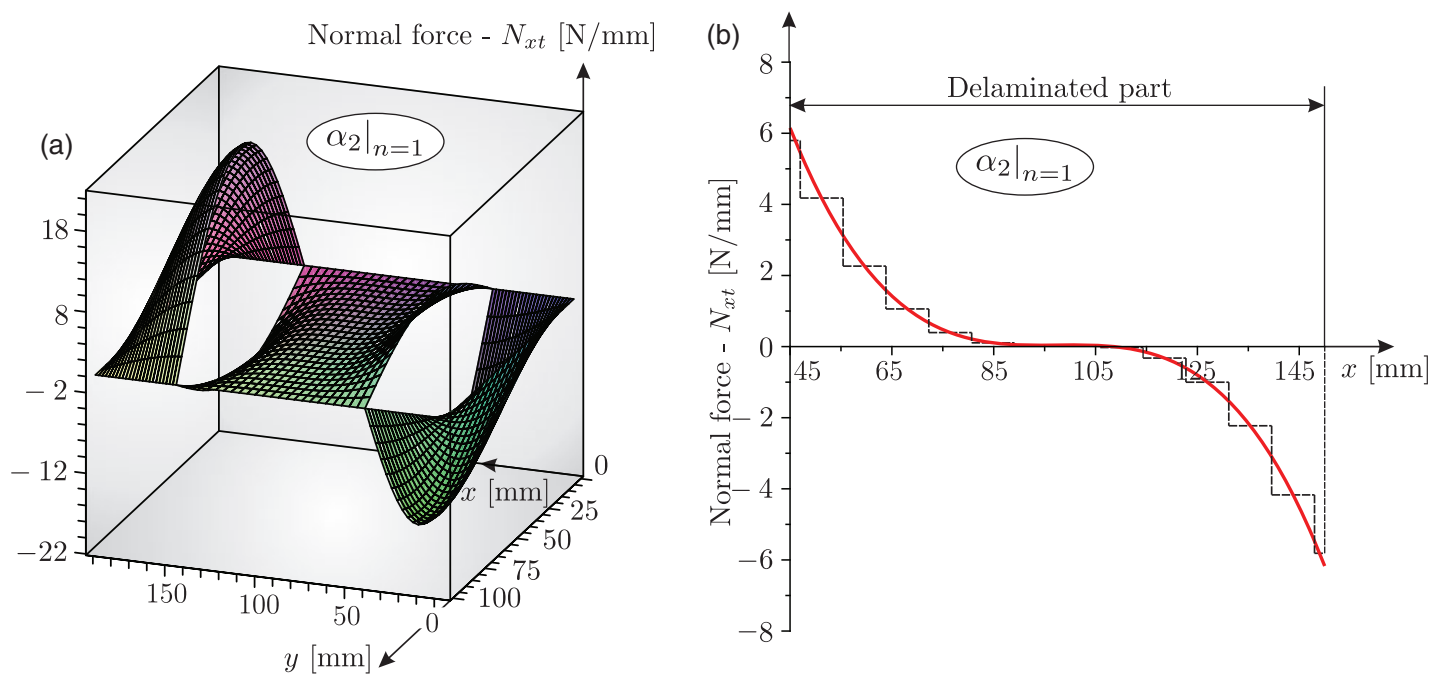

Figure 7. Distribution of the normal force, $N_{x t}$ in the top plate of the delaminated part of a simply supported plate in case IV, second vibration frequency (a). Piecewise constant approximation of the distribution for FE stability analysis (b).
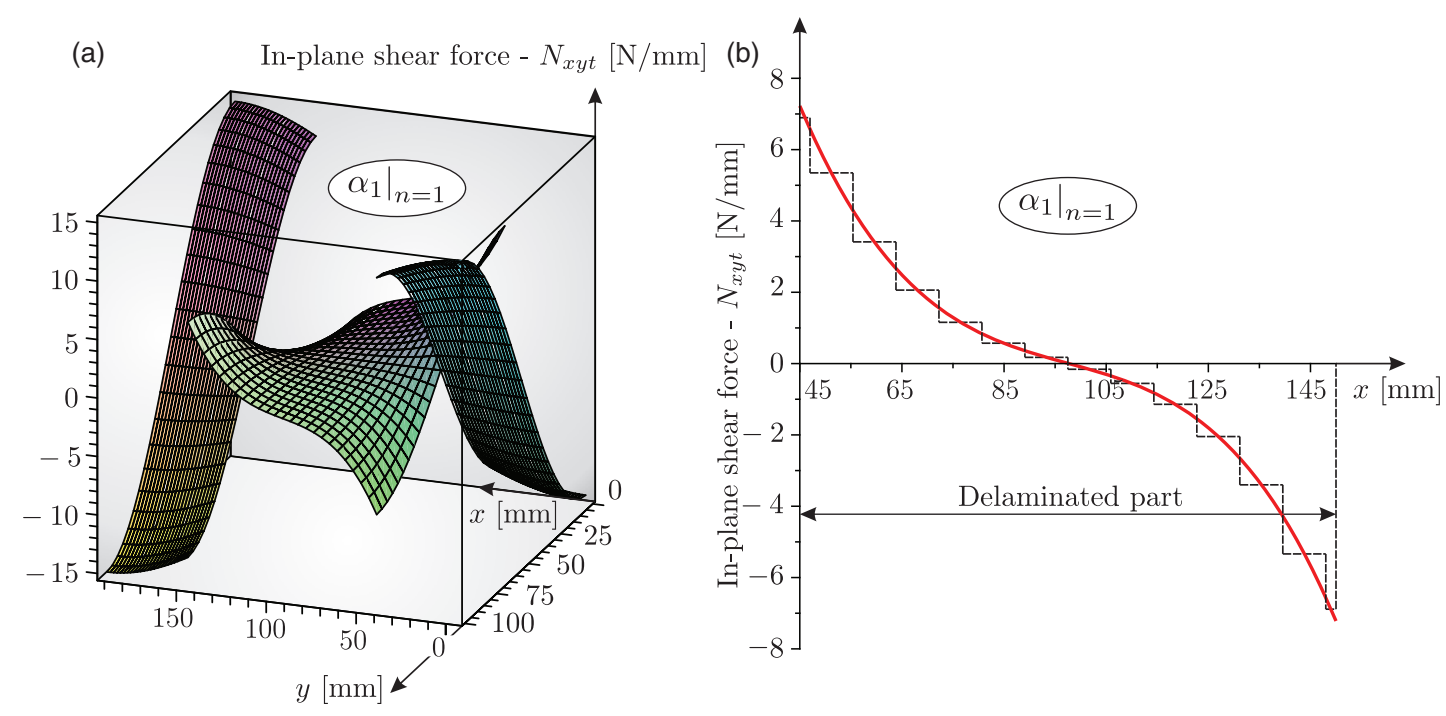

Figure 8. Distribution of the in-plane shear force, $N_{x y t}$ in the top plate of the delaminated part of a simply supported plate in case IV, first vibration frequency (a). Piecewise constant approximation of the distribution for FE stability analysis (b).

stability analysis by a piecewise constant description of the geometric stiffness. The approximated distributions along the delaminated part (3) are shown in Figures 6(b), 7(b), 8(b), and 9(b).

\section{Static and dynamic stability analysis}

It has to be noted that the eigenshapes are calculated from equation (56) considering static buckling with uniformly distributed forces in the $y$ direction. In other words the critical forces are calculated from dynamic stability analysis and the corresponding eigenshapes are associated to these eigenvalues by static stability calculation. First, equation (56) was solved using the piecewise constant distributions in Figures 6(b), 7(b), 8(b), and 9(b) in $x$ and uniform distribution in $y$. The critical forces of these computations are collected in the third columns of Tables 2 to 5 for cases I and II using the first two free vibration frequencies. Also, the top and bottom plates of the delaminated portion (3) were investigated separately in this respect. It can be seen that without any exception the first critical force of the bottom plate is always higher than the fourth critical force in the top plate. The second step was that the trigonometric distribution of the forces was considered using equation (57), 


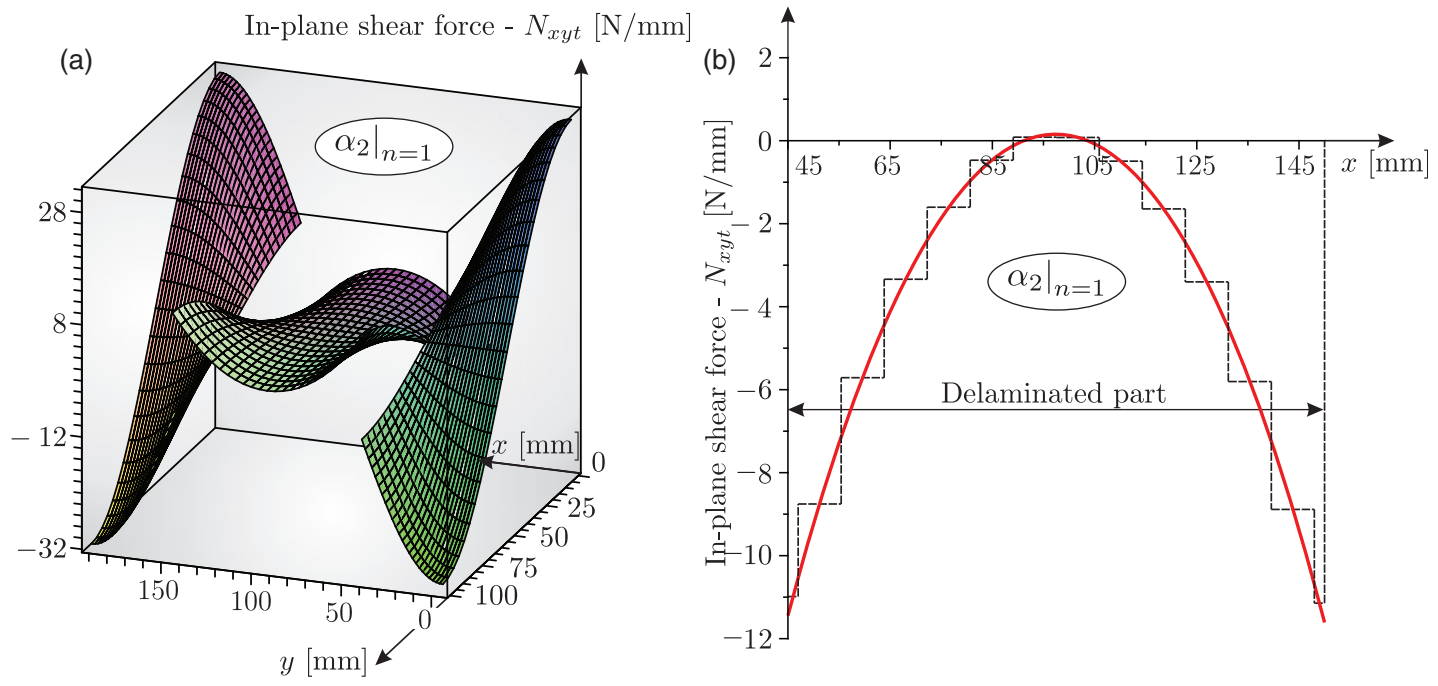

Figure 9. Distribution of the in-plane shear force, $N_{x y t}$ in the top plate of the delaminated part of a simply supported plate in case IV, second vibration frequency (a). Piecewise constant approximation of the distribution for FE stability analysis (b).
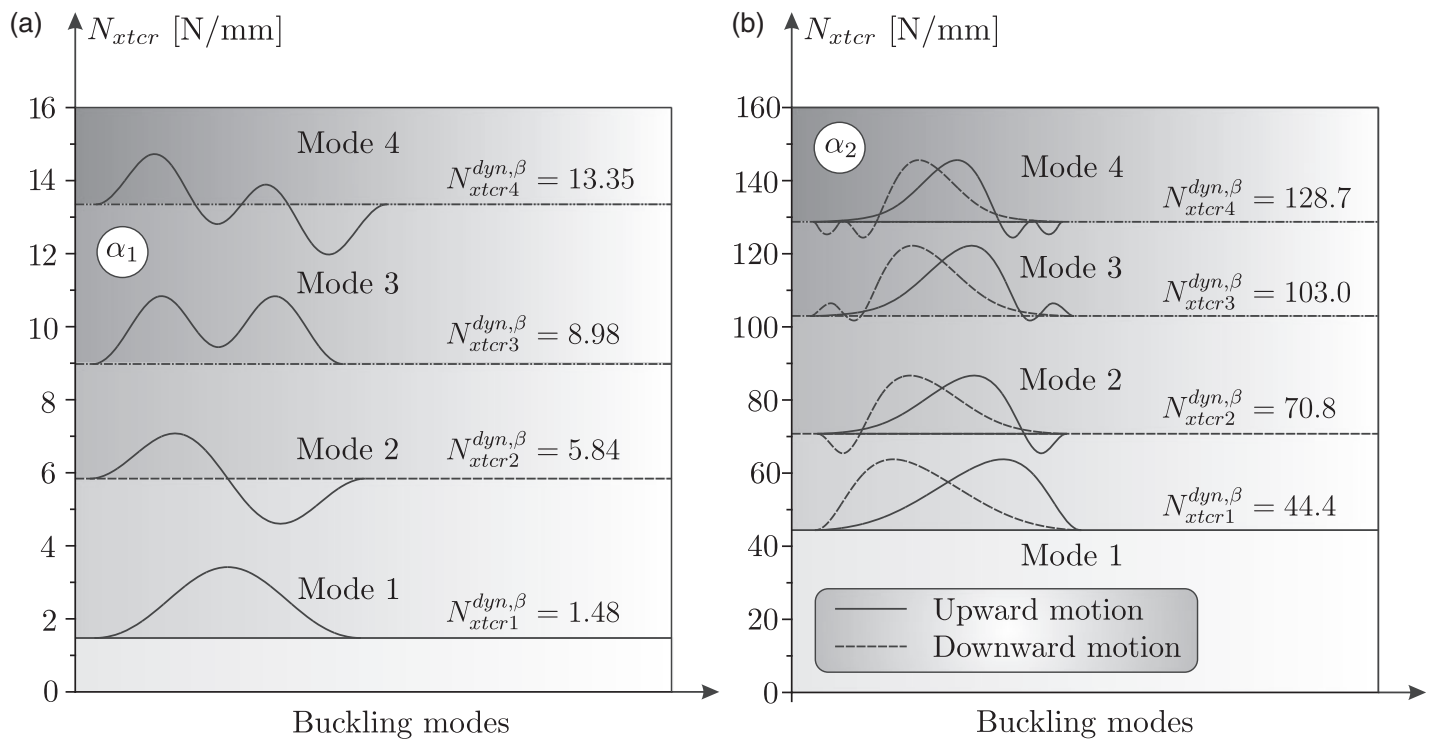

Figure 10. Subsequent appearance of the local buckling mode shapes and the estimated critical dynamic forces in case IV, first (a) and second (b) free vibration frequency of a simply supported plate with delamination.

the critical forces are calculated again and collected in the fourth columns of Tables 2 to 5 . The trigonometric load multiplicator $\left(\lambda_{\beta}\right)$ was calculated as the ratio of the two static loads and in each case $\lambda_{\beta}=1.414$ was obtained (refer to Tables 2 to 5). Thus, $41.4 \%$ higher critical loads are required if the widthwise distribution is trigonometric compared to the uniform loads. The third step was the solution of equation (61) to obtain the critical dynamic loads width uniform distribution in $y$, the results are in Tables 2 to 5 . In the fourth step the critical dynamic loads with trigonometric distribution in $y$ were estimated by producting those by step three with the multiplicator, $\lambda_{\beta}$. That was the way how the seventh column in Tables 2 to 5 was obtained. In the final stage the critical amplitudes were calculated for each buckling mode by comparing the critical loads to the distributions depicted in Figures 6, 7, 8, and 9 if the maximum amplitude of free vibration was $1 \mathrm{~mm}$. The reference value was the force in the left delamination tip in Figure 1. The critical amplitude means the amplitude at the point of the maximum deflection. 

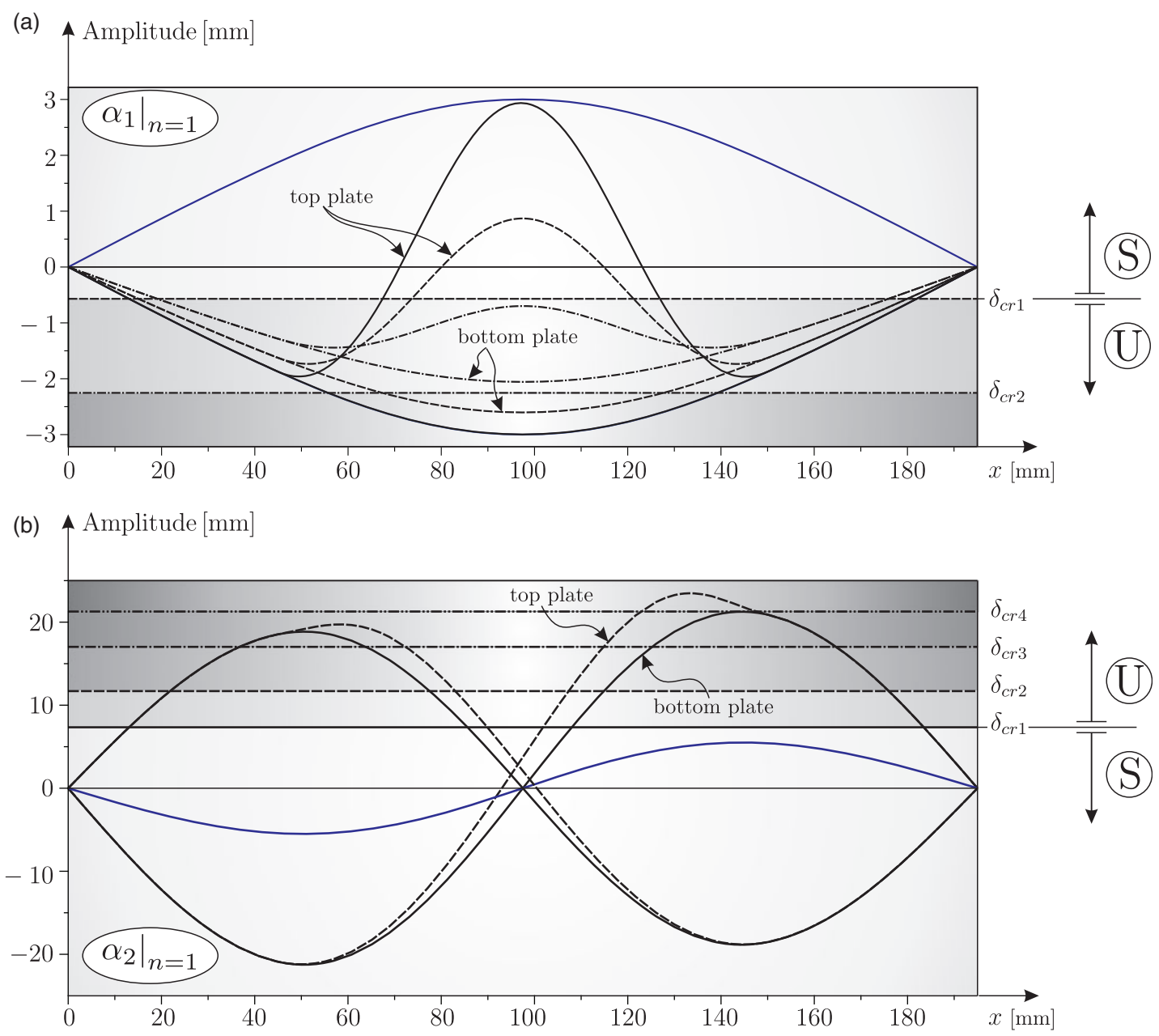

Figure II. Mode shape prediction with local delamination buckling for the first (a) and second (b) free vibration frequencies of case IV, simply supported edges. Note: the mode shapes involve a half sine wave in the $y$ direction.

For cases III and IV the critical forces are collected in Tables 6 to 9 including stability analysis with respect to $N_{x}$. The stability of the delaminated portion with respect to the in-plane shear force $N_{x y}$ was also carried out and the critical loads are summarized in Table 10. In cases I to III, only the static stability was performed because it can be seen that in each case significantly higher forces are required to the buckling than those for the top plate. It was necessary to investigate the critical forces in case IV. In accordance with Table 11 the critical forces $\left(N_{x y}\right)$ are relatively low for the first frequency of the top plate, however it can be seen that the first critical amplitude for $N_{x y}$ (Table 11) is less than the fourth for $N_{x}$ (Table 8). For the second frequency the critical $N_{x y}$ forces involve lower amplitudes compared to those presented in Table 9; however, the top plate always dominated the buckling phenomenon.

Figure 10 shows the first four critical load and the corresponding buckling eigenshapes in the case of the first and second natural vibration frequencies for the simply supported plate in case IV. In fact there is nothing special in the first frequency and the associated eigenshapes, they are as expected. However, if the second free vibration frequency is taken into account the corresponding force distributions are compressive for the half region and tensile in the other half region of the delaminated part (refer to Figure 7(b)). That is the reason for the unusual eigenshapes depicted in Figure 10(b). Another important aspect is that because of the compressive/tensile regions the delamination buckling can take place in both half time periods during the vibration. This is in contrast with the first frequency, where the buckling is kinematically possible only if the plate moves downwards.

\section{Mode shapes and phase plane portraits with delamination buckling}

The basic assumptions for the approximation of mode shapes and phase plane portraits were: the 

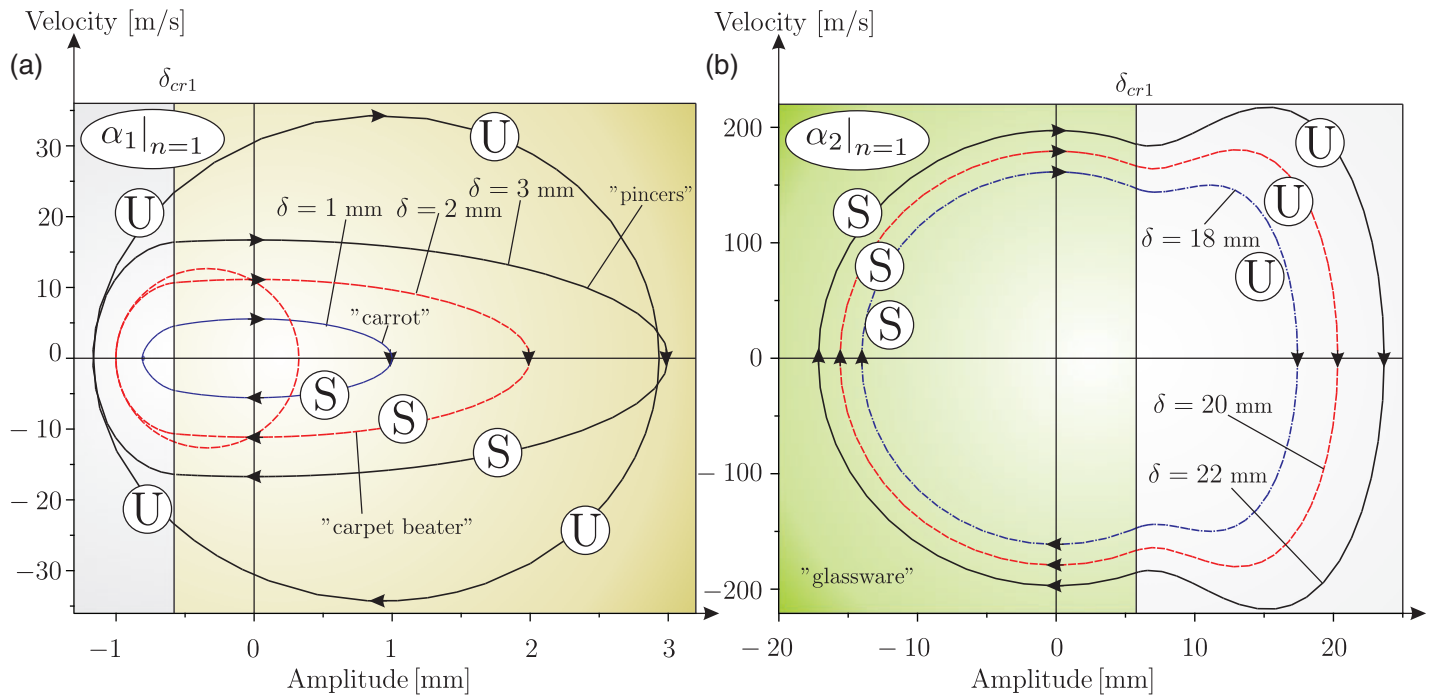

Figure 12. Phase plane portraits of the motion of $P_{1}$, first vibration frequency (a) and $P_{2}$, second free vibration frequency (b) in case $I V$, simply supported edges (refer to Figure I for the position of $P_{1}$ and $P_{2}$ ).

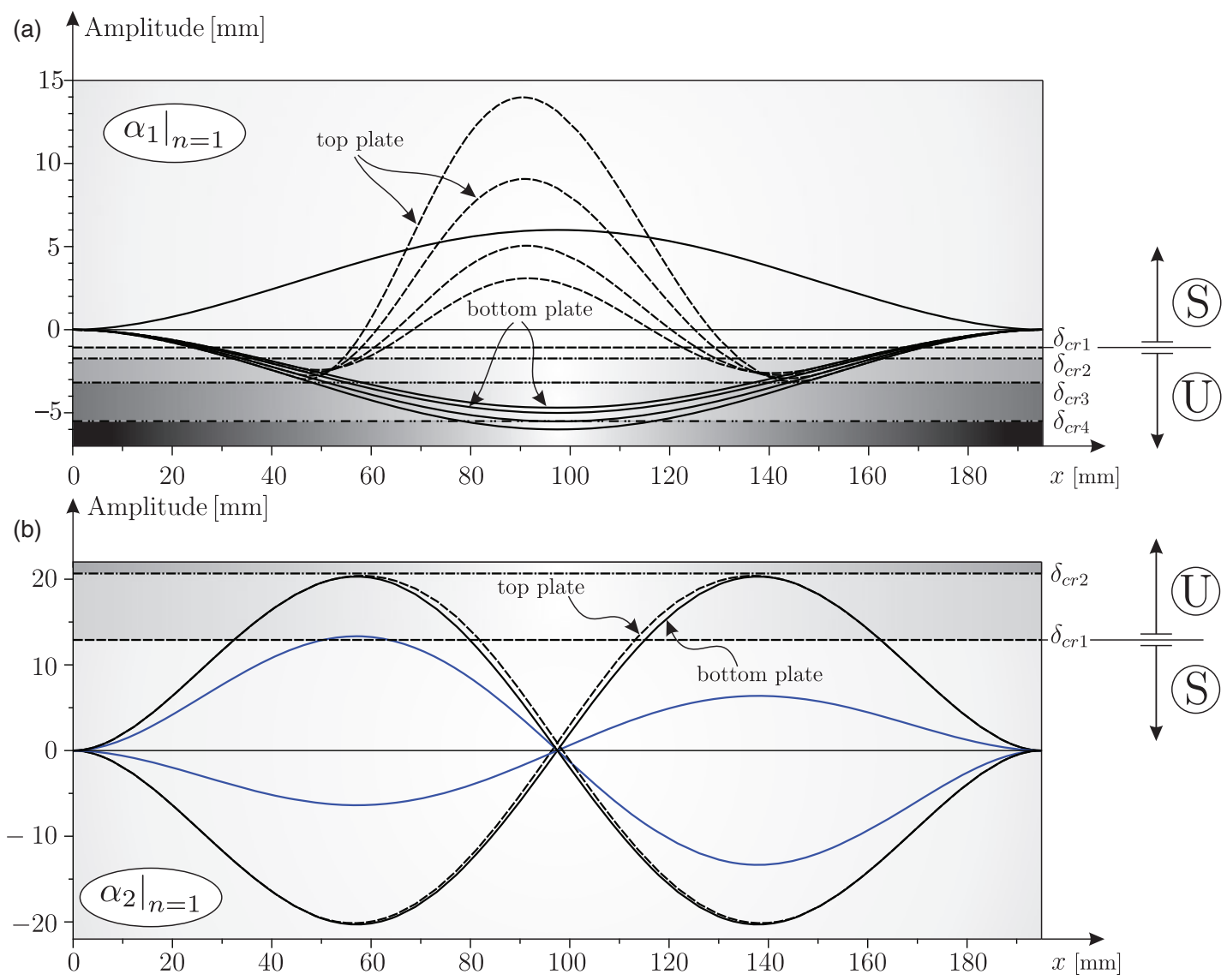

Figure 13. Mode shape prediction with local delamination buckling for the first $\left(\alpha_{1}=1 \mathrm{I} / 3 \mathrm{~Hz}\right)(\mathrm{a})$ and second $\left(\alpha_{2}=2403 \mathrm{~Hz}\right)(\mathrm{b})$ free vibration frequencies of case IV, built-in edges at $x=0$ and $x=L$. Note: the mode shapes involve a half sine wave in the $y$ direction. 

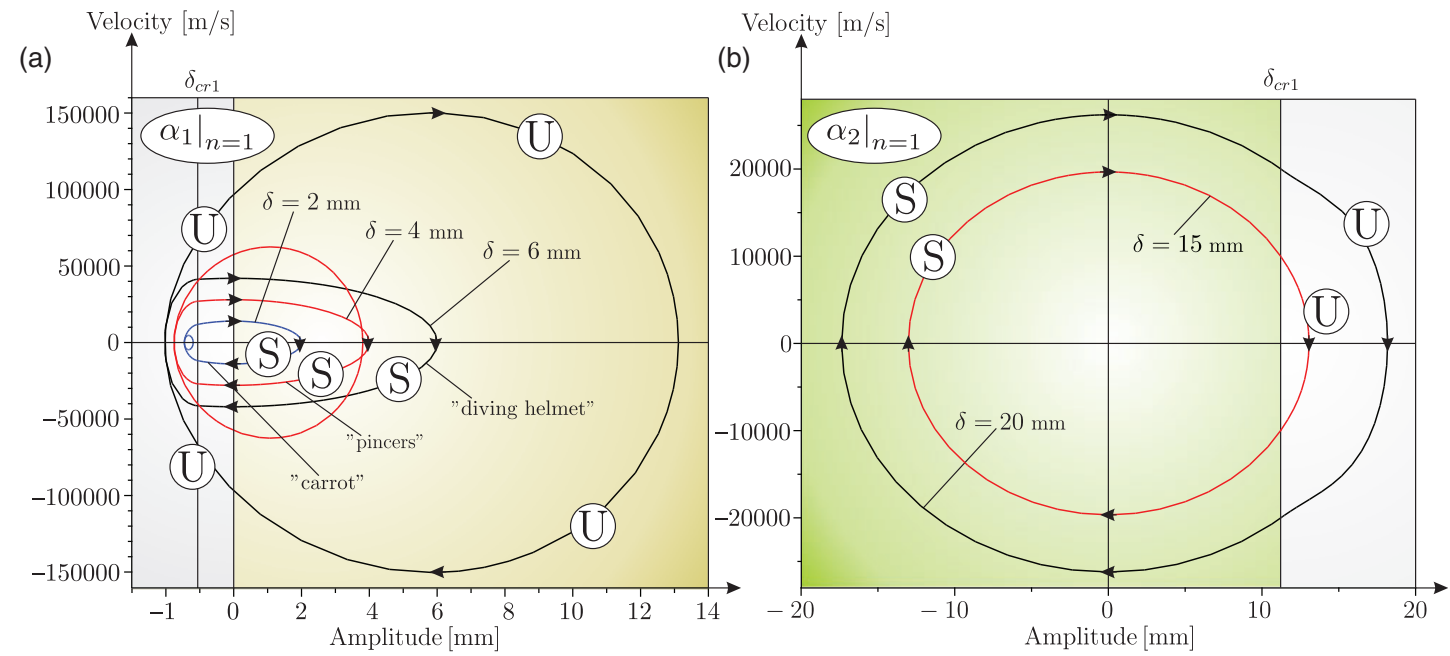

Figure 14. Phase plane portraits of the motion of $P_{1}$, first vibration frequency $\left(\alpha_{1}=1113 \mathrm{~Hz}\right)(a)$ and $P_{2}$, second free vibration frequency $\left(\alpha_{2}=2403 \mathrm{~Hz}\right)(\mathrm{b})$ in case IV, built-in edges at $x=0$ and $x=L$ (refer to Figure I for the position of $\mathrm{P}_{1}$ and $\mathrm{P}_{2}$ ).
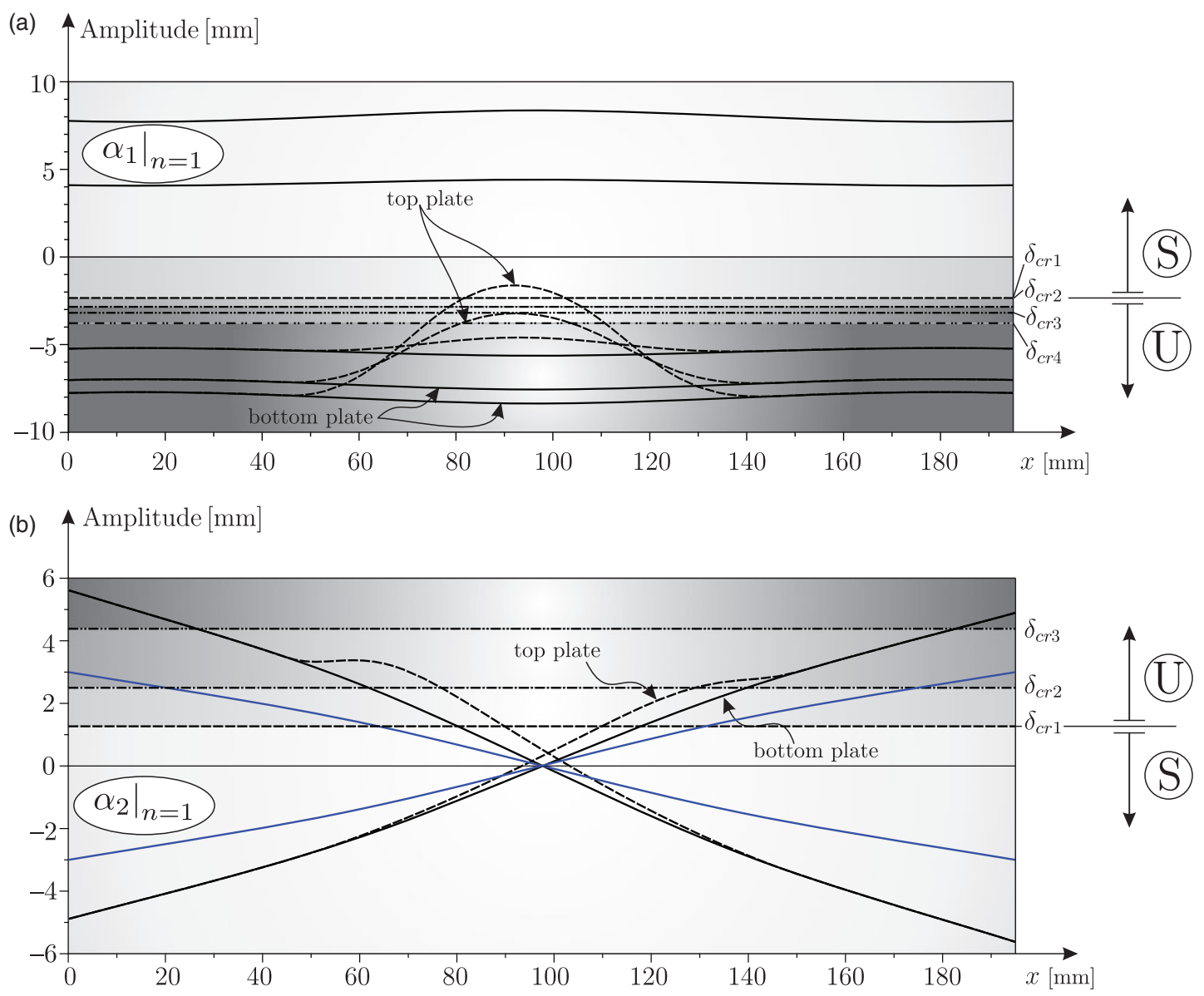

Figure I5. Mode shape prediction with local delamination buckling for the first $\left(\alpha_{1}=6 \mathrm{II} \mathrm{Hz}\right)(\mathrm{a})$ and second $\left(\alpha_{2}=872 \mathrm{~Hz}\right)(\mathrm{b})$ free vibration frequencies of case IV, free edges at $x=0$ and $x=L$. Note: the mode shapes involve a half sine wave in the $y$ direction. 

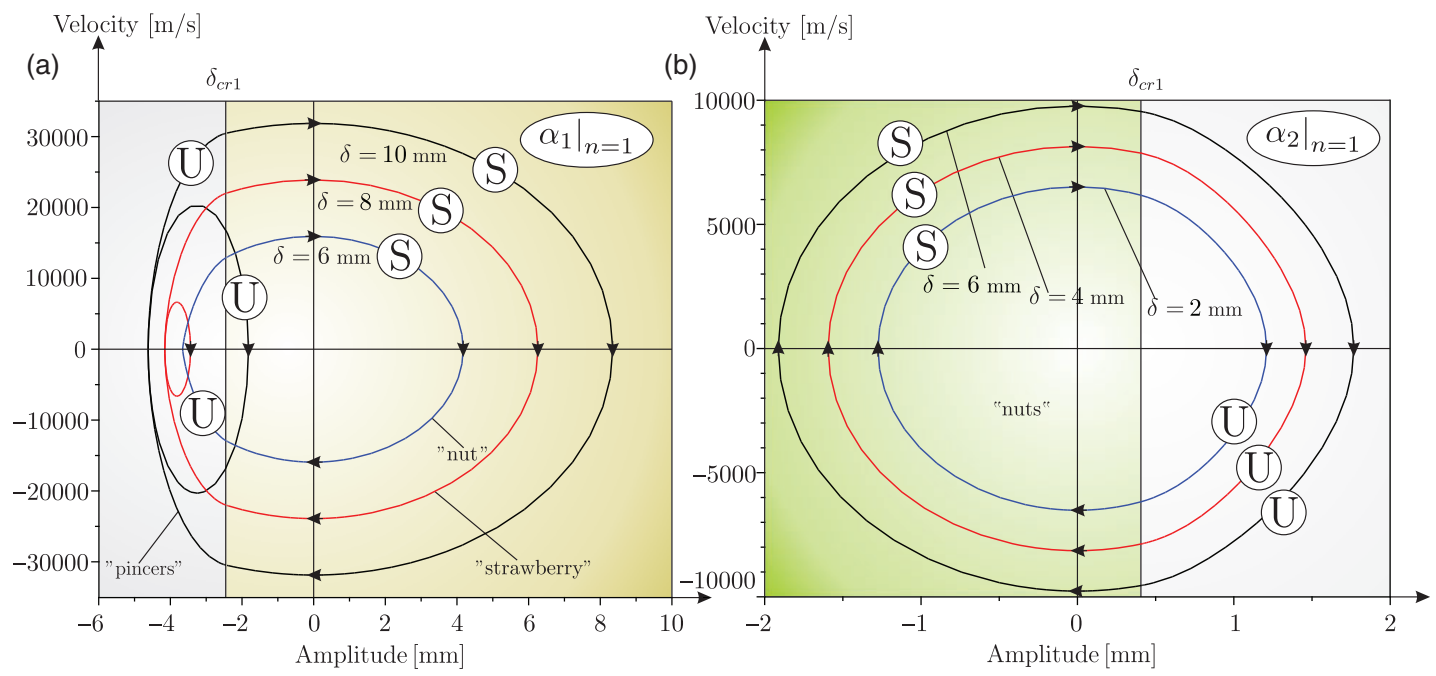

Figure 16. Phase plane portraits of the motion of $\mathrm{P}_{1}$, first vibration frequency $\left(\alpha_{1}=61 \mathrm{I} \mathrm{Hz}\right)(\mathrm{a})$ and $\mathrm{P}_{2}$, second free vibration frequency $\left(\alpha_{2}=872 \mathrm{~Hz}\right)(\mathrm{b})$ in case IV, free edges at $x=0$ and $x=L$ (refer to Figure I for the position of $\mathrm{P}_{1}$ and $\mathrm{P}_{2}$ ).

delamination buckling does not alter significantly the free vibration frequencies; moreover, the normal and in-plane shear force distributions can be approximated by the analytical model even if the delamination buckles and higher buckling modes appear locally. Finally, the delamination opening can be approximated by superimposing the free vibration and local buckling mode shapes. The mass of the top delaminated plate is $6.12 \%$ of the mass of the whole plate. Although buckling involves some nonlinearity, it is assumed that a linear superposition scheme approximates well the reality.

Using the critical amplitudes and the static eigenshapes the delamination buckling during vibration can be simulated. The buckled shape of the delamination relative to the free vibration mode shape was calculated by using an approximate arc length criterion. Based on the critical and the chosen maximum amplitudes (chosen to have small amplitude vibration) the arc length of the local buckling deflection, $s_{w t}$ was producted by a scale factor, $s_{f}$. At both amplitudes the axial displacements at the delamination tips, $u_{t}\left(L_{1}\right)$ and $u_{t}\left(L_{1}+a\right)$ were calculated and the relative axial displacement $\Delta U=\left|U_{t}\left(L_{1}\right)-U_{t}\left(L_{1}+a\right)\right|$ was determined for both amplitudes. The scale factors were chosen in order to satisfy the $s_{f} \cdot s_{w t}-\Delta U=a$ condition with at least two decimals accuracy for both amplitudes. Then, the average of the two scale factors was used. For the second buckling mode the same procedure was applied, the arc length from the first buckling mode was calculated by the average scale factor and the scale factors for the second buckling mode were calculated and averaged again in order the arc length of the buckled shape minus the relative axial displacements be equal to $a$.
For the third and fourth buckling modes the procedure was repeated. Actually it means a linearized model to approximate the arc lengths.

In Figure 11, the eigenshapes with delamination buckling are presented along the midline $(y=b / 2)$ of the simply supported plate. In direction $y$ the shapes are given by a sine function with a half wave. The shapes for case IV are plotted and the maximum vibration amplitude was chosen so that the first four critical forces and corresponding buckling eigenshapes appear. Essentially the instability takes place after the first critical amplitude is reached (refer to Table 8). Then the second buckling eigenshape is superimposed to the first one and so on. It can be stated that the first mode is the most dominant, the effect of the second mode is negligible and hard to recognize in the vibration eigenshape. As a consequence the higher buckling eigenshapes are not visible at all. Figure 11(b) shows the vibration mode shape for the second frequency. The critical loads and amplitudes are collected in Table 9. Although the delamination buckles in both half time periods, the mechanism and the scheme is the same as that for the first natural frequency. It was assumed that because of the small mass of the top plate in case IV the buckling does not influence essentially the global shape compared to the constrained mode vibration (no delamination opening) and even the node of the shape remains in the same position for the second mode. It has to be mentioned that although in accordance with Table 12 even the first buckling shape from $N_{x y}$ appears, its effect is negligible compared to the buckling shapes from $N_{x}$.

More information can be found on the motion by creating the phase plane portraits of some points 
located in the top plate of the delaminated region. It is the portrait of point $\mathrm{P}_{1}$ that is displayed in Figure 12(a) for the first frequency in case IV (refer to Figure 1 for the position of point $\mathrm{P}_{1}$ ). The shapes discovered in the trajectories are "carrot", "carpet beater" and "pincers", respectively. Similar results were obtained for beams in Szekrényes. ${ }^{82}$ The lobes appearing in the phase plane show the significant change in the amplitude and velocity of the points compared to the free vibration without delamination buckling. For the second frequency the phase plane portraits in Figure 12(b) show "glassware" shape trajectories in point $\mathrm{P}_{2}$ (refer to Figure 1). In each portrait the delamination buckling means the locally unstable motion.

The analysis reveals that the material defects can lead to parametric excitation, amplitude dependent vibration characteristics and nonlinearites even if the material is linear elastic in the global sense. The buckling is displacement controlled during the vibration, and so, it is unlikely that the local delamination buckling leads to catastrophic failure.

Some more examples were solved with different B.C.s as well. Figure 13 shows the free vibration mode shapes when the edges at $x=0$ and $x=L$ were built-in ends. The first two frequencies are considered leading to similar modes shapes to those by Figure 11. However, it has to be mentioned that the internal force distribution is different compared to the case of simply supported edges. The phase plane portraits depicted in Figure 14 show that the second vibration mode induces only very small changes for the chosen amplitudes. The free edges at $x=0$ and $x=L$ were also considered and the corresponding mode shapes can be seen in Figure 15. The relative delamination opening is the smallest in this case for both frequencies. The phase plane portraits plotted in Figure 16 involve "pincers", "nut", and "strawberry" shape trajectories for $\alpha_{1}$, moreover"nut" shape trajectories for $\alpha_{2}$.

\section{Conclusions}

In this paper, it was shown that the natural vibration induces parametric excitation in laminated elastic plates with delamination. The analysis was carried out in two steps. First, the constrained mode model was applied to investigate the free vibration frequencies and mode shapes without delamination buckling. It was shown that the distribution of the internal normal and in-plane shear forces is nonuniform along the whole plane of the delaminated part. If the system performs harmonic motion in time then the internal forces change periodically in the course of the vibration leading to the oscillatory change in the stiffness locally. In the second step the delaminated part was modeled by semi-discrete FE model, wherein the plate deflection was approximated by cubic (Hermitian) polynomials and linear interpolation was applied to the membrane displacements. The continuous solution in the $y$ direction was kept. The stiffness and mass matrices were determined in the traditional way formulating the strain and kinetic energy of the plate. The geometric stiffness matrices because of the internal normal and in-plane shear forces were calculated. The stability analysis was carried out for static condition providing the local buckling mode shapes, while the dynamic stability analysis was done in order to obtain the dynamic internal loads and the critical vibration amplitudes.

The mode shapes with delamination buckling were calculated for cases when the thickness of the top plate was relatively small compared to that of the bottom one. The local amplitude relative to the free vibration mode shape was computed based on a linearized arc length criterion. The kinematically possible mode shapes showed that the first buckling mode is the most dominant, and although it is possible that even higher modes appear during the harmonic motion, these are in fact not visible at all. In each case it was shown that the buckling takes place because of the normal forces and the stability limit related to the in-plane shear force is significantly higher. While for the first vibration mode the delamination buckles only in the downward motion of the plate, the second vibration mode involves the doublebuckling of the delamination in both half periods. The phase plane portraits of certain points located on the delaminated part were plotted and several trajectories were discovered depending on the boundary conditions and the first and second vibration frequencies of the plate.

The results of this paper show that the material defects can lead to internal parametric excitation and this phenomenon makes the vibration amplitude dependent. It should be mentioned that in general the dynamic stability calculation module is not implemented into the commercial FE packages, such analyses can be carried out only by user-written codes.

\section{Declaration of conflicting interests}

The author declared no potential conflicts of interest with respect to the research, authorship, and/or publication of this article.

\section{Funding}

This work was supported by the János Bolyai Research Scholarship of the Hungarian Academy of Sciences and the Hungarian National Scientific Research Fund (OTKA) under grant number 44615-066-15 (108414). 


\section{References}

1. Rizov V, Shipsha A and Zenkert D. Indentation study of foam core sandwich composite panels. Compos Struct 2005; 69: 95-102.

2. Rizov VI. Non-linear indentation behavior of foam core sandwich composite materials - A 2D approach. Comput Mater Sci 2006; 35: 107-115.

3. Sarvestani HY and Sarvestani MY. Free-edge stress analysis of general composite laminates under extension, torsion and bending. Appl Math Model 2012; 36: 1570-1588.

4. Burlayenko VN and Sadowski T. A numerical study of the dynamic response of sandwich plates initially damaged by low-velocity impact. Comput Mater Sci 2012; 52: 212-216.

5. Ahn JS, Kim YW and Woo KS. Analysis of circular free edge effect in composite laminates by p-convergent global-local model. Int J Mech Sci 2013; 66: 149-155.

6. Rhymer J, Kim H and Roach D. The damage resistance of quasi-isotropic carbon/epoxy composite tape laminates impacted by high velocity ice. Compos Part A: Appl Sci Manuf 2012; 43: 1134-1144.

7. Orbulov I, Kientzl I, Blücher J, et al. Production and investigation of a metal matrix composite pipe. In: Kollár L, Czigány $\mathrm{T}$ and Karger-Kocsis $\mathrm{J}$ (eds) Proceedings of 14th European conference on composite materials, Budapest, Hungary, 2010. Paper ID ECCM14-262, 2010.06.07-2010.06.10.

8. Czigány T and Deák T. Preparation and manufacturing techniques for macro- and microcomposites. Polym Compos 2012; 1: 111-134.

9. Hajikazemi M, Sadr MH, Hosseini-Toudeshky H, et al. Thermo-elastic constants of cracked symmetric laminates: A refined variational approach. Int $J$ Mech Sci 2014; 89: 47-57.

10. Hajikazemi M and Sadr M. Stiffness reduction of cracked general symmetric laminates using a variational approach. Int J Solids Struct 2014; 51: 1483-1493.

11. Hajikazemi M and Sadr M. A variational model for stress analysis in cracked laminates with arbitrary symmetric lay-up under general in-plane loading. Int $J$ Solids Struct 2014; 51: 516-529.

12. Dilena M and Morassi A. A damage analysis of steelconcrete composite beams via dynamic methods. Part II: Analytical models and damage detection. $J$ Vib Control 2003; 9: 529-565.

13. Dilena $\mathrm{M}$ and Morassi A. Experimental modal analysis of steel-concrete composite beams with partially damaged connection. J Vib Control 2004; 10: 897-913.

14. Manoach E, Samborski S, Mitura A, et al. Vibration based damage detection in composite beams under temperature variations using Poincaré maps. Int J Mech Sci 2012; 62: 120-132.

15. Hu N, Liu Y, Li Y, et al. Optimal excitation frequency of lamb waves for delamination detection in CFRP laminates. J Compos Mater 2010; 44: 1643-1663.

16. Grouve WJB, Warnet L, de Boer A, et al. Delamination detection with fibre Bragg gratings based on dynamic behaviour. Compos Sci Technol 2008; 68: 2418-2424.
17. Zou Y, Tong L and Steven GP. Vibration-based modeldependent damage (delamination) identification and health monitoring for composite structures-A review. J Sound Vib 2000; 230: 357-378.

18. Minak G, Palazzetti R, Trendafilova I, et al. Localization of a delamination and estimation of its length in a composite laminate beam by the VSHM and pattern recognition methods. Mech Compos Mater 2010; 46: 387-394.

19. Guechaichia A and Trendafilova I. A simple frequencybased delamination detection and localization method without baseline model. J Phys: Conf Ser 2012; 382: 1-7.

20. Zhang Z, Shankar K, Ray T, et al. Vibration-based inverse algorithms for detection of delamination in composites. Compos Struct 2013; 102: 226-236.

21. Shi PM, Li JZ, Jiang JS, et al. Nonlinear dynamics of torsional vibration for rolling mill's main drive system under parametric excitation. J Iron Steel Res Int 2013; 20: 7-12.

22. Yao Z, Mei D and Chen Z. Chatter suppression by parametric excitation: Model and experiments. J Sound Vib 2011; 330: 2995-3005.

23. Zatarain M, Alvarez J, Bediaga I, et al. Implicit subspace iteration as an efficient method to compute milling stability lobe diagrams. Int J Adv Manuf Technol 2014; 77: 597-607.

24. Shahgholi M and Khadem SE. Resonance analysis of gyroscopic nonlinear spinning shafts with parametric excitations and speed fluctuations. Int J Mech Sci 2012; 64: 94-109.

25. Szabó Z. Nonlinear vibrations of parametrically excited complex mechanical systems. Budapest University of Technology and Economics, Budapest, 2001.

26. Szabó $\mathrm{Z}$ and Lóránt G. Parametric excitation of a single railway wheelset. Veh Syst Dyn 2000; 33: 49-55.

27. Feng ZH, Lan XJ and Zhu XD. Principal parametric resonances of a slender cantilever beam subject to axial narrow-band random excitation of its base. Int $J$ NonLinear Mech 2007; 42: 1170-1185.

28. Feng ZH, Zhu XD and Lan XJ. Stochastic jump and bifurcation of a slender cantilever beam carrying a lumped mass under narrow-band principal parametric excitation. Int J Non-Linear Mech 2011; 46: 1330-1340.

29. El-Gohary HA and El-Ganaini WAA. Vibration suppression of a dynamical system to multi-parametric excitations via time-delay absorber. Appl Math Model 2012; 36: $35-45$.

30. Pellicano F. Dynamic instability of a circular cylindrical shell carrying a top mass under base excitation: Experiments and theory. Int J Solids Struct 2011; 48: 408-427.

31. Yan T, Kitipornchai S and Yang J. Parametric instability of functionally graded beams with an open edge crack under axial pulsating excitation. Compos Struct 2011; 93: 1801-1808.

32. Kim CH. Multi-mode parametric excitation of a simply supported plate under time-varying and non-uniform edge loading. Int J Non-Linear Mech 2010; 45: 149-158.

33. Han Q, Wang $\mathbf{J}$ and Li Q. Parametric instability of a cantilever beam subjected to two electromagnetic 
excitations: Experiments and analytical validation. $J$ Sound Vib 2011; 330: 3473-3487.

34. Luongo A and Zulli D. Parametric, external and selfexcitation of a tower under turbulent wind flow. $J$ Sound Vib 2011; 330: 3057-3069.

35. Ouni MHE, Kahla NB and Preumont A. Numerical and experimental dynamic analysis and control of a cable stayed bridge under parametric excitation. Eng Struct 2012; 45: 244-256.

36. Wu TX. Parametric excitation of wheel/track system and its effects on rail corrugation. Wear 2008; 265: 1176-1182.

37. Warminski J. Regular and chaotic vibrations of van der Pol and Rayleigh oscillators driven by parametric excitation. In: IUTAM Symposium on 50 years of chaos: Applied and theoretical, Procedia IUTAM, 2012, vol. 5, pp. 78-87.

38. Kovacic I and Zukovic M. A pendulum with an elliptictype parametric excitation: Stability charts for a damped and undamped system. Commun Nonlinear Sci Numer Simulat 2014; 19: 1185-1202.

39. Erdelyi NH and Hashemi SM. A dynamic stiffness element for free vibration analysis of delaminated layered beams. Model Simulat Eng 2012. Article ID 492415, 8 pp.

40. Baba BO and Gibson RF. The vibration response of composite sandwich beam with delamination. $A d v$ Compos Lett 2007; 16: 65-74.

41. Caddemi S and Calio I. Exact closed-form solution for the vibration modes of the Euler-Bernoulli beam with multiple open cracks. J Sound Vib 2009; 327: 473-489.

42. Çallioglu H, Atlihan $\mathrm{G}$ and Topçu M. Vibration analysis of multiple delaminated composite beams. Adv Compos Mater 2012; 21: 11-27.

43. Kiral BG. Free vibration analysis of delaminated composite beams. Sci Eng Compos Mater 2009; 16: 209-224.

44. Lee J. Free vibration analysis of delaminated composite beams. Comput Struct 2000; 74: 121-129.

45. Lee S, Park T and Voyiadjis GZ. Vibration analysis of multi-delaminated beams. Compos Part B: Eng 2003; 34 : 647-659.

46. Park T, Lee S and Voyiadjis GZ. Recurrent single delaminated beam model for vibration analysis of multidelaminated beams. J Eng Mech 2004; 130: 1072-1082.

47. Yazdi AA and Rezaeepazhand J. Structural similitude for vibration of delaminated composite beam-plates. Key Eng Mater 2010; 417-418: 749-752.

48. Chakraborty A, Mahapatra DR and Gopalakrishnan S. Finite element analysis of free vibration and wave propagation in asymmetric composite beams with structural discontinuities. Compos Struct 2002; 55: 23-26.

49. Zhu JF, Gu Y and Tong L. Formulation of reference surface element and its applications in dynamic analysis of delaminated composite beams. Compos Struct 2004; 68: 481-490.

50. Chen HP. Free vibration of prebuckled and postbuckled plates with delamination. Compos Sci Technol 1994; 51: 451-462.

51. Yin WL and Kane KC. Vibration of a delaminated beam-plate relative to buckled states. J Sound Vib 1992; 156: $125-140$.
52. Çallioglu H and Atlihan G. Vibration analysis of delaminated composite beams using analytical and FEM models. Indian J Eng Mater Sci 2011; 18: 7-14.

53. Hu N, Fukunaga H, Kameyama M, et al. Vibration analysis of delaminated composite beams and plates using a higher-order finite element. Int J Mech Sci 2002; 44: 1479-1503.

54. Kumar SK, Ganguli R and Harursampath D. Partial delamination modeling in composite beams using a finite element method. Finite Elem Anal Des 2013; 76: $1-12$.

55. Ramtekkar GS. Free vibration analysis of delaminated beams using mixed finite element model. J Sound Vib 2009; 328: 428-440.

56. Jafari-Talookolaei RA and Abedi M. Analytical solution for the free vibration analysis of delaminated Timoshenko beams. Scient World J 2014. Article ID: 280256.

57. Li S and Fan L. Free vibration of FGM Timoshenko beams with through-width delamination. Sci China Phys Mech Astron 2014; 57: 927-934.

58. Kargarnovin MH, Ahmadian MT and Jafari-Talookolaei RA. Forced vibration of delaminated Timoshenko beams subjected to a moving load. Sci Eng Compos Mater 2012; 19: $145-157$.

59. Kargarnovin MH, Jafari-Talookolaei RA and Ahmadian MT. Vibration analysis of delaminated Timoshenko beams under the motion of a constant amplitude point force traveling with uniform velocity. Int $J$ Mech Sci 2013; 70: 39-49.

60. Kargarnovin MH, Jafari-Talookolaei RA and Ahmadian MT. Analytical solution for the dynamic analysis of a delaminated composite beam traversed by a moving constant force. J Vib Control 2013; 19: 1524-1537.

61. Kargarnovin MH, Ahmadian MT and Jafari-Talookolaei RA. Forced vibration of delaminated Timoshenko beams under the action of moving oscillatory mass. Shock Vib 2013; 20: 79-96.

62. Kargarnovin MH, Ahmadian MT, Jafari-Talookolaei RA, et al. Semi-analytical solution for the free vibration analysis of generally laminated composite Timoshenko beams with single delamination. Compos Part B: Eng 2013; 45: 587-600.

63. Kargarnovin MH, Ahmadian MT, Jafari-Talookolaei RA, et al. Dynamics of a delaminated Timoshenko beam subjected to a moving oscillatory mass. Mech Based Des Struct Mach 2012; 40: 218-240.

64. Luo H and Hanagud S. Dynamics of delaminated beams. Int J Solids Struct 2000; 37: 1501-1519.

65. Matbuly MS, Ragb O and Nassar M. Natural frequencies of a functionally graded cracked beam using the differential quadrature method. Appl Math Comput 2009; 215: 2307-2316.

66. Perel VY. Finite element analysis of vibration of delaminated composite beam with an account of contact of the delamination crack faces, based on the first-order shear deformation theory. J Compos Mater 2005; 39: 1843-1876.

67. Perel VY. A new approach for finite element analysis of delaminated composite beam, allowing for fast and 
simple change of geometric characteristics of the delaminated area. Struct Eng Mech 2007; 25: 501-508.

68. Perel VY. A numerical-analytical solution for dynamics of composite delaminated beam with piezoelectric actuator, with account of nonpenetration constraint for the delamination crack faces. J Compos Mater 2005; 39: 67-103.

69. Mahieddine A and Ouali M. Modeling and analysis of beams with delamination. Int $J$ Model Simulat Scient Comput 2010; 1: 435-444.

70. Mahieddine A, Pouget $\mathbf{J}$ and Ouali M. Modeling and analysis of delaminated beams with integrated piezoelectric actuators. Comptes Rendus-Mecanique 2010; 338: 283-289.

71. Saravanos DA and Hopkins DA. Effects of delaminations on the damped characteristics of composite laminates: Analysis and experiments. J Sound Vib 1996; 192: 977-993.

72. Chrysochoidis NA and Saravanos DA. High-frequency dispersion characteristics of smart delaminated composite beams. J Intell Mater Syst Struct 2009; 20: 1057-1068.

73. Shu D and Fan H. Free vibration of bimaterial split beam. Compos Part B: Eng 1996; 27B: 76-84.

74. Shu D and Della CN. Vibrations of multiple delaminated beams. Compos Struct 2004; 64: 467-477.

75. Shu D and Della CN. Free vibration analysis of composite beams with two non-overlapping delaminations. Int $J$ Mech Sci 2004; 46: 509-526.

76. Shu D and Della CN. Vibration of delaminated multilayer beams. Compos Part B: Eng 2006; 37: 227-236.

77. Shu D and Della CN. Free vibration analysis of composite beams with overlapping delaminations. Eur J Mech A/ Solids 2005; 24: 491-503.

78. Liu Y and Shu DW. Analytical solution of the vibration of delaminated bimaterial beams fully or partially supported by elastic foundation. Appl Mech Mater 2013; 394: 75-79.

79. Shu D. Vibration of sandwich beams with double delaminations. Compos Sci Technol 1995; 54: 101-109.

80. Burlayenko VN and Sadowski T. Influence of skin/core debonding on free vibration behavior of foam and honeycomb cored sandwich plates. Int J Non-Linear Mech 2010; 45: 959-968.

81. Szekrényes A. Coupled flexural-longitudinal vibration of delaminated composite beams with local stability analysis. J Sound Vib 2014; 333: 5141-5164.

82. Szekrényes A. A special case of parametrically excited systems: free vibration of delaminated composite beams. Eur J Mech A/Solids 2015; 49: 82-105.

83. Ecsedi I and Baksa A. Static analysis of composite beams with weak shear connection. Appl Math Model 2011; 35: 1739-1750.

84. Lenci S and Clementi F. Effects of shear stiffness, rotatory and axial inertia, and interface stiffness on free vibrations of a two-layer beam. J Sound Vib 2012; 331: 5247-5267.

85. Lenci S and Rega G. An asymptotic model for the free vibrations of a two-layer beam. Eur $J$ Mech A/Solids 2013; 42: 441-453.
86. Nguyen QH, Martinelli E and Hjiaj M. Derivation of the exact stiffness matrix for a two-layer Timoshenko beam element with partial interaction. Eng Struct 2011; 33: 298-307.

87. Vo TP and Thai HT. Vibration and buckling of composite beams using refined shear deformation theory. Int J Mech Sci 2012; 62: 67-76.

88. Singha MK and Daripa R. Nonlinear vibration and dynamic stability analysis of composite plates. $J$ Sound Vib 2009; 328: 541-554.

89. Wang $\mathbf{J}$ and Tong L. A study of the vibration of delaminated beams using a nonlinear anti-interpenetration constraint model. Compos Struct 2002; 57: 483-488.

90. Zak AJ. Non-linear vibration of a delaminated composite beam. Key Eng Mater 2005; 293-294: 607-614.

91. Szekrényes A. Analysis of classical and first-order shear deformable cracked orthotropic plates. J Compos Mater 2014; 48: 1441-1457.

92. Szekrényes A. Interface crack between isotropic Kirchhoff plates. Meccanica 2013; 48: 507-526.

93. Endo M. Study on an alternative deformation concept for the Timoshenko beam and Mindlin plate models. Int J Eng Sci 2015; 87: 32-46.

94. Batista M. Comparison of Reissner, Mindlin and Reddy plate models with exact three dimensional solution for simply supported isotropic and transverse inextensible rectangular plate. Meccanica 2012; 47: 257-268.

95. Batista M. Refined Mindlin-Reissner theory of forced vibrations of shear deformable plates. Eng Struct 2011; 33: 265-272.

96. Szekrényes A. The system of exact kinematic conditions and application to delaminated first-order shear deformable composite plates. Int J Mech Sci 2013; 77: $17-29$.

97. Daneshmehr A, Nateghi A and Inman D. Free vibration analysis of cracked composite beams subjected to coupled bending-torsion loads based on a first order shear deformation theory. Appl Math Model 2013; 37: 10074-10091.

98. Petrolito J. Vibration and stability analysis of thick orthotropic plates using hybrid-Trefftz elements. Appl Math Model 2014; 338: 5858-5869.

99. Tian B, Li R and Zhong Y. Integral transform solutions to the bending problems of moderately thick rectangular plates with all edges free resting on elastic foundations. Appl Math Model 2014. DOI: 10.1016/ j.apm.2014.05.012.

100. Endo M and Kimura N. An alternative formulation of the boundary value problem for the Timoshenko beam and Mindlin plate. J Sound Vib 2007; 301: 355-373.

101. Shahrjerdi A, Mustapha F, Bayat M, et al. Free vibration analysis of solar functionally graded plates with temperature-dependent material properties using second order shear deformation theory. J Mech Sci Technol 2011; 25: 1-15.

102. Shahrjerdi A, Bayat M, Mustapha F, et al. Second-order shear deformation theory to analyze stress distribution for solar functionally graded plates. Mech Based Des Struct Mach 2010; 38: 348-361. 
103. Izadi $\mathbf{M}$ and Tahani $\mathbf{M}$. Analysis of interlaminar stresses in general cross-ply laminates with distributed piezoelectric actuators. Compos Struct 2010; 92: 757-768.

104. Szekrényes A. Interface fracture in orthotropic composite plates using second-order shear deformation theory. Int J Damage Mech 2013; 22: 1161-1185.

105. Szekrényes A. Antiplane-inplane shear mode delamination between two second-order shear deformable composite plates. Math Mech Solids 2015. DOI: 10.1177/ 1081286515581871.

106. Szekrényes A. Stress and fracture analysis in delaminated orthotropic composite plates using third-order shear deformation theory. Appl Math Model 2014; 38: 3897-3916.

107. Aragh BS, Farahani EB and Barati AN. Natural frequency analysis of continuously graded carbon nanotube-reinforced cylindrical shells based on third-order shear deformation theory. Math Mech Solids 2013; 18: 264-284.

108. Talha M and Singh BN. Static response and free vibration analysis of FGM plates using higher order shear deformation theory. Appl Math Model 2010; 34: 3991-4011.

109. Szekrényes A. Application of Reddy's third-order theory to delaminated orthotropic composite plates. Eur J Mech A/Solids 2014; 43: 9-24.

110. Szekrényes A. Bending solution of third-order orthotropic Reddy plates with asymmetric interfacial crack. Int J Solids Struct 2014; 51: 2598-2619.

111. Oktem AS, Alankaya V and Soares CG. Boundary-discontinuous Fourier analysis of simply supported crossply plates. Appl Math Model 2013; 37: 1378-1389.

112. Taj MNAG, Chakrabarti A and Sheikh AH. Analysis of functionally graded plates using higher order shear deformation theory. Appl Math Model 2013; 37: 8484-8494.

113. Thai CH, Tran LV, Tran DT, et al. Analysis of laminated composite plates using higher-order shear deformation plate theory and node-based smoothed discrete shear gap method. Appl Math Model 2012; 36: 5657-5677.

114. Thai HT and Vo TP. A new sinusoidal shear deformation theory for bending, buckling, and vibration of functionally graded plates. Appl Math Model 2013; 37: 3269-3281.

115. Thai HT and Choi DH. Analytical solutions of refined plate theory for bending, buckling and vibration analyses of thick plates. Appl Math Model 2013; 37: 8310-8323.

116. Saeedi N, Sab K and Caron JF. Delaminated multilayered plates under uniaxial extension. Part I: Analytical analysis using a layerwise stress approach. Int J Solids Struct 2012; 49: 3711-3726.

117. Saeedi N, Sab K and Caron JF. Delaminated multilayered plates under uniaxial extension. Part II: Efficient layerwise mesh strategy for the prediction of delamination onset. Int $J$ Solids Struct 2012; 49: 3727-3740.

118. Saeedi N, Sab K and Caron JF. Cylindrical bending of multilayered plates with multi-delamination via a layerwise stress approach. Compos Struct 2013; 95: 728-739.

119. Saeedi N, Sab K and Caron JF. Stress analysis of long multilayered plates subjected to invariant loading: Analytical solutions by a layerwise stress model. Compos Struct 2013; 100: 307-322.

120. Marjanović M and Vuksanović D. Layerwise solution of free vibrations and buckling of laminated composite and sandwich plates with embedded delaminations. Compos Struct 2014; 108: 9-20.

121. Marjanović M and Vuksanović D. Transient analysis of laminated composite and sandwich plates with embedded delaminations using GLPT. In: Proceedings of the 9th international conference on structural dynamics, EURODYN 2014, Porto, Portugal, 2014, pp. 3373-3380.

122. Alibeigloo A and Zanoosi AAP. Static analysis of rectangular nano-plate using three-dimensional theory of elasticity. Appl Math Model 2013; 37: 7016-7026.

123. Chang $\mathrm{HH}$ and Tarn JQ. Three-dimensional elasticity solutions for rectangular orthotropic plates. J Elasticity 2012; 108: 49-66.

124. Singh VK and Panda SK. Nonlinear free vibration analysis of single/doubly curved composite shallow shell panels. Thin-Walled Struct 2014; 85: 341-349.

125. Panda SK and Singh BN. Nonlinear free vibration of spherical shell panel using higher order shear deformation theory - A finite element approach. Int J Press Vess Piping 2009; 86: 373-383.

126. Panda SK and Singh BN. Large amplitude free vibration analysis of thermally post-buckled composite doubly curved panel using nonlinear FEM. Finite Elem Anal Des 2011; 47: 378-386.

127. Diaz AD, Caron JF and Ehrlacher A. Analytical determination of the modes I, II and III energy release rates in a delaminated laminate and validation of a delamination criterion. Compos Struct 2007; 78: 424-432.

128. Alvarez-Lima R, Diaz-Diaz A, Caron JF, et al. Enhanced layerwise model for laminates with imperfect interfaces - Part 1: Equations and theoretical validation. Compos Struct 2012; 94: 1694-1702.

129. Lerpiniere A, Caron JF, Diaz AD, et al. The $\{\mathrm{LS} 1\}$ model for delamination propagation in multilayered materials at interfaces: A comparison between experimental and finite elements strain energy release rates. Int J Solids Struct 2014; 51: 3973-3986.

130. Hatch MR. Vibration simulation using MATLAB and ANSYS. Boca Raton, London, New York, Washington, D.C.: Chapman \& Hall/CRC, 2001.

131. Hills DA, Kelly PA, Dai DN, et al. Solution of crack problems, the distributed dislocation technique. Dordrecht, Boston, London: Kluwer Academic Publishers, 1996.

132. Reddy JN. Mechanics of laminated composite plates and shells - Theory and analysis. Boca Raton, London, New York, Washington D.C.: CRC Press, 2004.

133. Chou PC and Pagano NJ. Elasticity - Tensor, dyadic, and engineering approaches. Princeton, New Jersey, Toronto, London: D. Van Nostrand Company, Inc, 1967. 
134. Kollár LP and Springer GS. Mechanics of composite structures. Cambridge, New York, Melbourne, Madrid, Cape Town, Singapore, São Paolo: Cambridge University Press, 2003.

135. Hwu C. Anisotropic elastic plates. New York, Dordrecht, Heidelberg, London: Springer, 2010.

136. Mujumdar PM and Suryanarayan S. Flexural vibration of beams with delaminations. J Sound Vib 1988; 125: 441-461.

137. Bodaghi M and Saidi AR. Lévy-type solution for buckling analysis of thick functionally graded rectangular plates based on the higher-order shear deformation plate theory. Appl Math Model 2010; 34: 3659-3673.

138. Hajheidari H and Mirdamadi HR. Frequency-dependent vibration analysis of symmetric cross-ply laminated plate of Levy-type by spectral element and finite strip procedures. Appl Math Model 2013; 37: 7193-7205.

139. Ye JQ. Laminated composite plates and shells -3D modelling. London, Berlin, Heidelberg, New York, Hong Kong, Milan, Paris, Tokyo: Springer, 2003.

140. Garvan F. The Maple book. Boca Raton, London, New York, Washington D.C.: Chapman \& Hall/CRC, 2002.

141. Petyt M. Introduction to finite element vibration analysis, 2nd ed. Cambridge, New York, Melbourne, Madrid, Cape Town, Singapore, São Paulo, Delhi, Dubai, Tokyo, Mexico City: Cambridge University Press, 2010.

142. Bathe KJ. Finite element procedures. Upper Saddle River, NJ: Prentice Hall, 1996.

143. Bolotin WW. Kinetische stabilität elastischer systeme. Berlin: VEB Deutscher Verlag der Wissenschaften, 1961.

144. Radu AG and Chattopadhyay A. Dynamic stability analysis of composite plates including delaminations using a higher order theory and transformation matrix approach. Int $J$ Solids Struct 2002; 39: 1949-1965.

145. Briseghella L, Majorana CE and Pellegrino C. Dynamic stability of elastic structures: A finite element approach. Comput Struct 1998; 69: 11-25.

146. Saravia CM, Machado SP and Cortínez VH. Free vibration and dynamic stability of rotating thin-walled composite beams. Eur J Mech A/Solids 2011; 30: 432-441.

147. Chattopadhyay A and Radu AG. Dynamic instability of composite laminates using a higher order theory. Comput Struct 2000; 77: 453-460.

\section{Appendix 1}

\section{Coefficients for the analytical state-space model}

The coefficients for equation (18) and the state-space model given by equation (17) are collected in this appendix

$$
\begin{aligned}
& \hat{a}_{1}=A_{11 t}+A_{11 b}, \hat{a}_{2}=A_{66 t}+A_{66 b}, \\
& \hat{a}_{3}=A_{12 t}+A_{12 b}+A_{66 t}+A_{66 b} \\
& \hat{a}_{4}=-\frac{1}{2} A_{11 t} t_{b}-B_{11 t}+\frac{1}{2} A_{11 b} t_{t}-B_{11 b}
\end{aligned}
$$

$$
\begin{aligned}
\hat{a}_{5}= & -\frac{1}{2}\left(A_{12 t}+A_{66 t}\right) t_{b}-\left(B_{12 t}+B_{66 t}\right) \\
& +\frac{1}{2}\left(A_{12 b}+A_{66 b}\right) t_{t}-\left(B_{12 b}+B_{66 b}\right) \\
\hat{a}_{6}= & -\hat{I}_{0}, \hat{a}_{7}=-\hat{I}_{1}
\end{aligned}
$$

$\hat{b}_{1}=\hat{a}_{3}, \quad \hat{b}_{2}=\hat{a}_{2}, \quad \hat{b}_{3}=A_{22 t}+A_{22 b}, \quad \hat{b}_{4}=\hat{a}_{5}$

$\hat{b}_{5}=-\frac{1}{2} A_{22 t} t_{b}-B_{22 t}+\frac{1}{2} A_{22 b} t_{t}-B_{22 b}$

$\hat{b}_{6}=-\hat{I}_{0}, \quad \hat{b}_{7}=-\hat{I}_{1}$

$$
\begin{aligned}
\hat{c}_{1}= & -\hat{a}_{4}, \quad \hat{c}_{2}=\hat{c}_{3}=\hat{a}_{5}, \quad \hat{c}_{4}=-\hat{b}_{5} \\
\hat{c}_{5}= & -D_{11 t}-D_{11 b}-B_{11 t} t_{b} \\
& +B_{11 b} t_{t}-\frac{1}{4} A_{11 t} t_{b}^{2}-\frac{1}{4} A_{11 b} t_{t}^{2}
\end{aligned}
$$

$$
\begin{aligned}
\hat{c}_{6}= & -2\left(D_{12 t}+D_{12 b}+2 D_{66 t}+2 D_{66 b}\right. \\
& \left.-\left(B_{12 t}+2 B_{66 t}\right) t_{b}+\left(B_{12 b}+2 B_{66 b}\right) t_{t}\right) \\
& -\frac{1}{2}\left(\left(A_{12 t}+2 A_{66 t}\right) t_{b}^{2}+\left(A_{12 b}+2 A_{66 b}\right) t_{t}^{2}\right)
\end{aligned}
$$

$\hat{c}_{7}=-D_{22 t}-D_{22 b}-B_{22 t} t_{b}+B_{22 b} t_{t}$

$$
-\frac{1}{4} A_{22 t} t_{b}^{2}-\frac{1}{4} A_{22 b} t_{t}^{2}
$$$$
\hat{c}_{8}=\hat{c}_{9}=-\hat{I}_{1}, \quad \hat{c}_{10}=\hat{c}_{11}=\hat{I}_{2}, \quad \hat{c}_{12}=-\hat{I}_{0}
$$

$$
\begin{aligned}
& \hat{h}_{1}=\frac{\hat{a}_{2} \beta^{2}+\hat{a}_{6} \alpha^{2}}{\hat{a}_{1}}, \\
& \hat{h}_{2}=\frac{\hat{a}_{2} \beta}{\hat{a}_{1}}, \quad \hat{h}_{3}=\frac{\hat{a}_{5} \beta^{2}+\hat{a}_{7} \alpha^{2}}{\hat{a}_{1}}, \quad \hat{h}_{4}=-\frac{\hat{a}_{4}}{\hat{a}_{1}}
\end{aligned}
$$

$$
\begin{aligned}
& \hat{j_{1}}=\frac{\hat{b}_{1} \beta}{\hat{b}_{2}}, \quad \hat{j}_{2}=\frac{\hat{b}_{3} \beta^{2}+\hat{b}_{6} \alpha^{2}}{\hat{b}_{2}}, \\
& \hat{j}_{3}=\frac{\beta\left(\hat{b}_{5} \beta^{2}+\hat{b}_{7} \alpha^{2}\right)}{\hat{b}_{2}}, \quad \hat{j}_{4}=-\frac{\hat{b}_{4} \beta}{\hat{b}_{2}}
\end{aligned}
$$

$$
\hat{n}_{1}=-\frac{-\hat{c}_{2} \beta^{2}-\hat{c}_{3} \hat{j}_{1} \beta-\hat{c}_{8} \alpha^{2}+\hat{c}_{1}\left(\hat{h}_{1}+\hat{h}_{2} \hat{j}_{1}\right)}{\hat{c}_{1} \hat{h}_{4}+\hat{c}_{5}}
$$

$$
\hat{n}_{2}=-\frac{-\hat{c}_{3} \hat{j}_{2} \beta+\hat{c}_{4} \beta^{3}+\hat{c}_{9} \beta \alpha^{2}+\hat{c}_{1} \hat{h}_{2} \hat{j}_{2}}{\hat{c}_{1} \hat{h}_{4}+\hat{c}_{5}}
$$

$$
\hat{n}_{3}=-\frac{-\hat{c}_{3} \hat{j}_{3} \beta+\hat{c}_{7} \beta^{4}+\hat{c}_{11} \alpha^{2} \beta^{2}-\hat{c}_{12} \alpha^{2}+\hat{c}_{1} \hat{h}_{2} \hat{j}_{3}}{\hat{c}_{1} \hat{h}_{4}+\hat{c}_{5}}
$$

$$
\hat{n}_{4}=-\frac{-\hat{c}_{3} \hat{j}_{4} \beta-\hat{c}_{6} \beta^{2}-\hat{c}_{10} \alpha^{2}+\hat{c}_{1} \hat{h}_{2} \hat{j}_{4}+\hat{c}_{1} \hat{h}_{3}}{\hat{c}_{1} \hat{h}_{4}+\hat{c}_{5}}
$$




\section{Appendix 2}

Critical static and dynamic loads for cases III and IV

Table 6. Critical static and dynamic $N_{x \delta}$ loads of a simply supported plate for the first free vibration frequency - case III (refer to Table 2 for the notations).

\begin{tabular}{|c|c|c|c|c|c|c|c|}
\hline $\begin{array}{l}\alpha_{1}^{a n} \\
(\mathrm{~Hz})\end{array}$ & $\begin{array}{l}\alpha_{1}^{F E M} \\
(\mathrm{~Hz})\end{array}$ & $\begin{array}{l}N_{x t, c r}^{s t a t} \\
(\mathrm{~N} / \mathrm{mm})\end{array}$ & $\begin{array}{l}N_{x t, c r}^{\text {stat } \beta} \\
(\mathrm{N} / \mathrm{mm})\end{array}$ & $\begin{array}{l}\lambda_{\beta} \\
\text { (I) }\end{array}$ & $\begin{array}{l}N_{x t, c r}^{d y n} \\
(\mathrm{~N} / \mathrm{mm})\end{array}$ & $\begin{array}{l}N_{x t, c r}^{d y n, \beta} \\
(\mathrm{N} / \mathrm{mm})\end{array}$ & $\begin{array}{l}\delta_{\text {crit }} \\
(\mathrm{mm})\end{array}$ \\
\hline \multirow[t]{4}{*}{854} & 854 & 15.9 & 22.5 & $1.4 \mid 4$ & 42.5 & 60.0 & 2.17 \\
\hline & & 27.6 & 39.1 & 1.414 & 51.5 & 72.8 & 2.63 \\
\hline & & 52.9 & 74.9 & 1.414 & 80.3 & 113.6 & 4.10 \\
\hline & & 79.9 & 113.0 & 1.414 & 102.9 & 145.5 & 5.25 \\
\hline$\alpha_{1}^{a n}$ & $\alpha_{1}^{F E M}$ & $N_{x b, c r}^{\text {stat }}$ & $N_{x b, c r}^{s t a t, \beta}$ & $\lambda_{\beta}$ & $N_{x b, c r}^{d y n}$ & $N_{x b, c r}^{d y n, \beta}$ & $\delta_{\text {crit }}$ \\
\hline$(\mathrm{Hz})$ & $(\mathrm{Hz})$ & $(\mathrm{N} / \mathrm{mm})$ & $(\mathrm{N} / \mathrm{mm})$ & (I) & $(\mathrm{N} / \mathrm{mm})$ & $(\mathrm{N} / \mathrm{mm})$ & $(\mathrm{mm})$ \\
\hline 854 & 854 & 627.6 & 887.5 & 1.414 & 643.0 & 909.2 & 30.1 \\
\hline
\end{tabular}

Table 7. Critical static and dynamic $N_{x \delta}$ loads of a simply supported plate for the second free vibration frequency - case III (refer to Table 2 for the notations).

\begin{tabular}{|c|c|c|c|c|c|c|c|}
\hline $\begin{array}{l}\alpha_{1}^{a n} \\
(\mathrm{~Hz})\end{array}$ & $\begin{array}{l}\alpha_{1}^{F E M} \\
(\mathrm{~Hz})\end{array}$ & $\begin{array}{l}N_{x t, c r}^{\text {stat }} \\
(\mathrm{N} / \mathrm{mm})\end{array}$ & $\begin{array}{l}N_{x t, c r}^{\text {stat, } \beta} \\
(\mathrm{N} / \mathrm{mm})\end{array}$ & $\begin{array}{l}\lambda_{\beta} \\
\text { (I) }\end{array}$ & $\begin{array}{l}N_{x t, c r}^{d y n} \\
(\mathrm{~N} / \mathrm{mm})\end{array}$ & $\begin{array}{l}N_{x t, c r}^{d y n, \beta} \\
(\mathrm{N} / \mathrm{mm})\end{array}$ & $\begin{array}{l}\delta_{\text {crit }} \\
(\mathrm{mm})\end{array}$ \\
\hline \multirow{4}{*}{1512} & $151 \mid$ & II 5.5 & 163.3 & 1.414 & 88.0 & 124.4 & 41.3 \\
\hline & & I76.I & 249.0 & $1.4 \mid 4$ & 209.4 & 296.1 & 98.2 \\
\hline & & 473.6 & 669.8 & 1.414 & 275.6 & 389.8 & 129.3 \\
\hline & & 925.5 & 1308.9 & 1.414 & 313.4 & 443.2 & 147.0 \\
\hline$\alpha_{1}^{a n}$ & $\alpha_{1}^{F E M}$ & $N_{x b, c r}^{s t a t}$ & $N_{x b, c r}^{s t a t, \beta}$ & $\lambda_{\beta}$ & $N_{x b, c r}^{d y n}$ & $N_{x b, c r}^{d y n, \beta}$ & $\delta_{\text {crit }}$ \\
\hline$(\mathrm{Hz})$ & $(\mathrm{Hz})$ & $(\mathrm{N} / \mathrm{mm})$ & $(\mathrm{N} / \mathrm{mm})$ & (I) & $(\mathrm{N} / \mathrm{mm})$ & $(\mathrm{N} / \mathrm{mm})$ & $(\mathrm{mm})$ \\
\hline 1512 & $|5| \mid$ & 721.3 & 1020 & $1.4 \mid 4$ & 568.2 & 803.4 & 435.2 \\
\hline
\end{tabular}

Table 8. Critical static and dynamic $N_{x \delta}$ loads of a simply supported plate for the first free vibration frequency - case IV (refer to Table 2 for the notations).

\begin{tabular}{|c|c|c|c|c|c|c|c|}
\hline $\begin{array}{l}\alpha_{1}^{a n} \\
(\mathrm{~Hz})\end{array}$ & $\begin{array}{l}\alpha_{1}^{F E M} \\
(\mathrm{~Hz})\end{array}$ & $\begin{array}{l}N_{x t, c r}^{s t a t} \\
(\mathrm{~N} / \mathrm{mm})\end{array}$ & $\begin{array}{l}N_{x t, c r}^{\text {stat } \beta} \\
(\mathrm{N} / \mathrm{mm})\end{array}$ & $\begin{array}{l}\lambda_{\beta} \\
\text { (I) }\end{array}$ & $\begin{array}{l}N_{x t, c r}^{d y n} \\
(\mathrm{~N} / \mathrm{mm})\end{array}$ & $\begin{array}{l}N_{x t, c r}^{d y n, \beta} \\
(\mathrm{N} / \mathrm{mm})\end{array}$ & $\begin{array}{l}\delta_{c r i t} \\
(\mathrm{~mm})\end{array}$ \\
\hline \multirow[t]{4}{*}{886} & 887 & 0.76 & 1.08 & 1.414 & 1.04 & I.48 & 0.57 \\
\hline & & 1.03 & 1.46 & 1.414 & 4.13 & 5.84 & 2.25 \\
\hline & & 1.76 & 2.50 & 1.414 & 6.35 & 8.98 & 3.46 \\
\hline & & 2.38 & 3.37 & 1.414 & 9.44 & 13.35 & 5.15 \\
\hline$\alpha_{1}^{a n}$ & $\alpha_{\mathrm{I}}^{F E M}$ & $N_{x b, c r}^{s t a t}$ & $N_{x b, c r}^{s t a t, \beta}$ & $\lambda_{\beta}$ & $N_{x b, c r}^{d y n}$ & $N_{x b, c r}^{d y n, \beta}$ & $\delta_{\text {crit }}$ \\
\hline$(\mathrm{Hz})$ & $(\mathrm{Hz})$ & $(\mathrm{N} / \mathrm{mm})$ & $(\mathrm{N} / \mathrm{mm})$ & (I) & $(\mathrm{N} / \mathrm{mm})$ & $(\mathrm{N} / \mathrm{mm})$ & $(\mathrm{mm})$ \\
\hline 886 & 887 & 888.4 & 1256 & 1.414 & 833.5 & 1178 & 479 \\
\hline
\end{tabular}


Table 9. Critical static and dynamic $N_{x \delta}$ loads of a simply supported plate for the second free vibration frequency - case IV (refer to Table 2 for the notations).

\begin{tabular}{|c|c|c|c|c|c|c|c|}
\hline $\begin{array}{l}\alpha_{1}^{a n} \\
(\mathrm{~Hz})\end{array}$ & $\begin{array}{l}\alpha_{1}^{F E M} \\
(\mathrm{~Hz})\end{array}$ & $\begin{array}{l}N_{x t, c r}^{\text {stat }} \\
(\mathrm{N} / \mathrm{mm})\end{array}$ & $\begin{array}{l}N_{x t, c r}^{\text {stat } \beta} \\
(\mathrm{N} / \mathrm{mm})\end{array}$ & $\begin{array}{l}\lambda_{\beta} \\
\text { (I) }\end{array}$ & $\begin{array}{l}N_{x t, c r}^{d y n} \\
(\mathrm{~N} / \mathrm{mm})\end{array}$ & $\begin{array}{l}N_{x t, c r}^{d y n, \beta} \\
(\mathrm{N} / \mathrm{mm})\end{array}$ & $\begin{array}{l}\delta_{\text {crit }} \\
(\mathrm{mm})\end{array}$ \\
\hline \multirow[t]{4}{*}{1829} & 1829 & 8.0 & 11.3 & 1.414 & 31.4 & 44.4 & 7.34 \\
\hline & & 20.6 & 29.1 & 1.414 & 50.0 & 70.8 & 11.7 \\
\hline & & 47.1 & 66.7 & 1.414 & 72.8 & 103.0 & 17.0 \\
\hline & & 81.1 & II 4.7 & 1.414 & 91.0 & 128.7 & 21.3 \\
\hline$\alpha_{1}^{a n}$ & $\alpha_{1}^{F E M}$ & $N_{x b, c r}^{\text {stat }}$ & $N_{x b, c r}^{s t a t, \beta}$ & $\lambda_{\beta}$ & $N_{x b, c r}^{d y n}$ & $N_{x b, c r}^{d y n, \beta}$ & $\delta_{\text {crit }}$ \\
\hline$(\mathrm{Hz})$ & $(\mathrm{Hz})$ & $(\mathrm{N} / \mathrm{mm})$ & $(\mathrm{N} / \mathrm{mm})$ & (I) & $(\mathrm{N} / \mathrm{mm})$ & $(\mathrm{N} / \mathrm{mm})$ & $(\mathrm{mm})$ \\
\hline 1829 & 1829 & 8040 & 11370 & 1.414 & 6856 & 9694 & 1122 \\
\hline
\end{tabular}

Table 10. Critical static $N_{x y \delta}$ loads of a simply supported plate for the first and second free vibration frequencies - cases I, II, and III.

\begin{tabular}{|c|c|c|c|c|c|c|c|}
\hline Case & $\alpha_{i}$ & $\begin{array}{l}\text { Frequency } \\
(\mathrm{Hz})\end{array}$ & $\begin{array}{l}N_{x y t, c r}^{\text {stat }} \\
(\mathrm{N} / \mathrm{mm})\end{array}$ & $\begin{array}{l}N_{x y t, c r}^{\text {stat } \beta} \\
(\mathrm{N} / \mathrm{mm})\end{array}$ & $\begin{array}{l}N_{x y b, c r}^{\text {stat }} \\
(\mathrm{N} / \mathrm{mm})\end{array}$ & $\begin{array}{l}N_{x y b, c r}^{\text {stat }, \beta} \\
(\mathrm{N} / \mathrm{mm})\end{array}$ & $\begin{array}{l}\lambda_{\beta} \\
\text { (I) }\end{array}$ \\
\hline \multirow[t]{2}{*}{ Case I } & $\alpha_{1}^{a n}$ & 753 & 412.5 & 583.4 & 2113 & 2988 & 1.414 \\
\hline & $\alpha_{2}^{a n}$ & 1355 & 543.2 & 768.3 & 3930 & 5570 & 1.414 \\
\hline \multirow[t]{2}{*}{ Case II } & $\alpha_{1}^{a n}$ & 792 & 182.7 & 258.3 & 2305 & 3260 & 1.414 \\
\hline & $\alpha_{2}^{a n}$ & 1420 & 270.8 & 383.0 & 3748 & 5300 & 1.414 \\
\hline \multirow[t]{2}{*}{ Case III } & $\alpha_{1}^{a n}$ & 854 & 81.0 & 114.5 & 2227 & 3150 & 1.414 \\
\hline & $\alpha_{2}^{a n}$ & 1512 & 148.3 & 209.8 & 2551 & 3609 & 1.414 \\
\hline
\end{tabular}

$\alpha_{i}^{a n}$ : free vibration frequency by analytical solution.

$N_{x y \delta, c r}^{\text {stat }}$ : critical load under static condition and uniform widthwise distribution.

$N_{x y \delta, c r}^{\text {stat }, \beta}$ critical load under static condition and sinusoidal widthwise distribution.

$\lambda_{\beta}$ : trigonometric load multiplicator.

Table II. Critical static and dynamic $N_{x y \delta}$ loads of a simply supported plate for the first free vibration frequency - case IV.

\begin{tabular}{|c|c|c|c|c|c|c|c|}
\hline $\begin{array}{l}\alpha_{1}^{a n} \\
(\mathrm{~Hz})\end{array}$ & $\begin{array}{l}\alpha_{1}^{\mathrm{FEM}} \\
(\mathrm{Hz})\end{array}$ & $\begin{array}{l}N_{x y t, c r}^{\text {stat }} \\
(\mathrm{N} / \mathrm{mm})\end{array}$ & $\begin{array}{l}N_{x y t, c r}^{\text {stat, }} \\
(\mathrm{N} / \mathrm{mm})\end{array}$ & $\begin{array}{l}\lambda_{\beta} \\
\text { (I) }\end{array}$ & $\begin{array}{l}N_{x y t, c r}^{d y n} \\
(\mathrm{~N} / \mathrm{mm})\end{array}$ & $\begin{array}{l}N_{x y t, c r}^{d y n, \beta} \\
(\mathrm{N} / \mathrm{mm})\end{array}$ & $\begin{array}{l}\delta_{c r i t} \\
(\mathrm{~mm})\end{array}$ \\
\hline \multirow[t]{4}{*}{886} & 887 & 5.81 & 8.2 & 1.414 & 31.4 & 44.4 & 6.51 \\
\hline & & 55.6 & 78.6 & $1.4 \mid 4$ & 110.5 & 156.2 & 24.1 \\
\hline & & 106.9 & 151.2 & 1.414 & 180.4 & 255.2 & 39.4 \\
\hline & & 166.9 & 236.0 & 1.414 & 247.6 & 350.0 & 54.0 \\
\hline$\alpha_{1}^{a n}$ & $\alpha_{1}^{F E M}$ & $N_{x y b, c r}^{\text {stat }}$ & $N_{x y b, c r}^{s t a t, \beta}$ & $\lambda_{\beta}$ & $N_{x y b, c r}^{d y n}$ & $N_{x y b, c r}^{d y n, \beta}$ & $\delta_{c r i t}$ \\
\hline$(\mathrm{Hz})$ & $(\mathrm{Hz})$ & $(\mathrm{N} / \mathrm{mm})$ & $(\mathrm{N} / \mathrm{mm})$ & (I) & $(\mathrm{N} / \mathrm{mm})$ & $(\mathrm{N} / \mathrm{mm})$ & $(\mathrm{mm})$ \\
\hline 886 & 887 & 8407 & 11,890 & $1.4 \mid 4$ & 5936 & 8394 & 1253 \\
\hline
\end{tabular}

$\alpha_{1}^{a n}$ : first free vibration frequency by analytical solution.

$\alpha_{1}^{F E M}$ : first free vibration frequency by finite element solution.

$N_{x y \delta, c r}^{\text {stat }}$ : critical load under static condition and uniform widthwise distribution.

$N_{x y \delta, c r}^{\text {stat },}$ : critical load under static condition and sinusoidal widthwise distribution;

$\lambda_{\beta}$ : trigonometric load multiplicator.

$N_{x y \delta, c r}^{d y n}$ : critical load under dynamic condition and uniform widthwise distribution.

$N_{x y \delta, c r}^{d y, \beta}$ : estimated critical load under dynamic condition and sinusoidal widthwise distribution; $\delta_{\text {crit: }}$ critical amplitude 
Table 12. Critical static and dynamic $N_{x y \delta}$ loads of a simply supported plate for the second free vibration frequency - case IV (refer to Table II for the notations).

\begin{tabular}{|c|c|c|c|c|c|c|c|}
\hline $\begin{array}{l}\alpha_{1}^{a n} \\
(\mathrm{~Hz})\end{array}$ & $\begin{array}{l}\alpha_{I}^{F E M} \\
(\mathrm{~Hz})\end{array}$ & $\begin{array}{l}N_{x t, c r}^{\text {stat }} \\
(\mathrm{N} / \mathrm{mm})\end{array}$ & $\begin{array}{l}N_{x t, c r}^{\text {stat } \beta} \\
(\mathrm{N} / \mathrm{mm})\end{array}$ & $\begin{array}{l}\lambda_{\beta} \\
\text { (I) }\end{array}$ & $\begin{array}{l}N_{x t, c r}^{d y n} \\
(\mathrm{~N} / \mathrm{mm})\end{array}$ & $\begin{array}{l}N_{x t, c r}^{d y n, \beta} \\
(\mathrm{N} / \mathrm{mm})\end{array}$ & $\begin{array}{l}\delta_{\text {crit }} \\
(\mathrm{mm})\end{array}$ \\
\hline \multirow[t]{4}{*}{1829} & 1829 & 10.6 & 14.9 & 1.40 & 150.3 & 211.3 & 18.9 \\
\hline & & 81.4 & 114.0 & 1.40 & 204.2 & 286.0 & 25.6 \\
\hline & & 194.3 & 272.7 & 1.40 & 328.9 & 461.6 & 41.3 \\
\hline & & 313.1 & 442.8 & $1.4 \mid 4$ & 513.3 & 726.0 & 65.0 \\
\hline$\alpha_{1}^{a n}$ & $\alpha_{1}^{F E M}$ & $N_{x b, c r}^{s t a t}$ & $N_{x b, c r}^{s t a t, \beta}$ & $\lambda_{\beta}$ & $N_{x b, c r}^{d y n}$ & $N_{x b, c r}^{d y n, \beta}$ & $\delta_{\text {crit }}$ \\
\hline$(\mathrm{Hz})$ & $(\mathrm{Hz})$ & $(\mathrm{N} / \mathrm{mm})$ & $(\mathrm{N} / \mathrm{mm})$ & (I) & $(\mathrm{N} / \mathrm{mm})$ & $(\mathrm{N} / \mathrm{mm})$ & $(\mathrm{mm})$ \\
\hline 1829 & 1829 & 24,463 & 9456 & $1.4 \mid 4$ & 27,968 & 39,547 & 3578 \\
\hline
\end{tabular}

